Article

\title{
Metal-organic frameworks MOF-808-X as highly efficient catalysts for direct synthesis of dimethyl carbonate from $\mathrm{CO}_{2}$ and methanol
}

\author{
Keng Xuan a,b, Yanfeng Pu a, Feng Li a, Jing Luo a,b, Ning Zhao a,*, Fukui Xiao a,\# \\ a State Key Laboratory of Coal Conversion, Institute of Coal Chemistry, Chinese Academy of Sciences, Taiyuan 030001, Shanxi, China \\ b University of Chinese Academy of Sciences, Beijing 100049, China
}

A R T I C L E I N F

Article history:

Received 8 November 2018

Accepted 26 December 2018

Published 5 April 2019

\section{Keywords:}

Metal-organic frameworks

MOF-808

Micropore size

Carbon dioxide utilization

Dimethyl carbonate

\begin{abstract}
A B S T R A C T
A series of metal-organic frameworks MOF-808-X (6-connected) were synthesized by regulating the $\mathrm{ZrOCl}_{2} \cdot 8 \mathrm{H}_{2} \mathrm{O} / 1,3,5$-benzenetricarboxylic acid (BTC) molar ratio (X) and tested for the direct synthesis of dimethyl carbonate (DMC) from $\mathrm{CO}_{2}$ and $\mathrm{CH}_{3} \mathrm{OH}$ with 1,1,1-trimethoxymethane (TMM) as a dehydrating agent. The effect of the $\mathrm{ZrOCl}_{2} \cdot 8 \mathrm{H}_{2} \mathrm{O} / \mathrm{BTC}$ molar ratio on the physicochemical properties and catalytic performance of MOF-808-X was investigated. Results showed that a proper $\mathrm{ZrOCl}_{2} \cdot 8 \mathrm{H}_{2} \mathrm{O} / \mathrm{BTC}$ molar ratio during MOF-808-X synthesis was fairly important to reduce the redundant BTC or zirconium clusters trapped in the micropores of MOF-808-X. MOF-808-4, with almost no redundant BTC or zirconium clusters trapped in the micropores, exhibited the largest surface area, micropore size, and the number of acidic-basic sites, and consequently showed the best activity among all MOF-808-X, with the highest DMC yield of $21.5 \%$ under the optimal reaction conditions. Moreover, benefiting from the larger micropore size, MOF-808-4 outperformed our previously reported UiO-66-24 (12-connected), which had even more acidic-basic sites and larger surface area than MOF-808-4, mainly because the larger micropore size of MOF-808-4 provided higher accessibility for the reactant to the active sites located in the micropores. Furthermore, a possible reaction mechanism over MOF-808-4 was proposed based on the in situ FT-IR results. The effects of different reaction parameters on DMC formation and the reusability of MOF-808-X were also studied.
\end{abstract}

(C) 2019, Dalian Institute of Chemical Physics, Chinese Academy of Sciences. Published by Elsevier B.V. All rights reserved.

\section{Introduction}

Dimethyl carbonate (DMC) is an environmentally benign chemical compound with versatile chemical properties and is widely used in many fields. For example, DMC can be used as a green solvent, electrolyte in lithium ion batteries, and an alternative to some toxic substances such as phosgene, dimethyl sulphate, and alkyl halide used in carbonylation and methylation reactions. DMC can also be used as a fuel additive owing to its high oxygen content and octane value [1-3]. Several pathways for DMC synthesis, including phosgene $\left(\mathrm{COCl}_{2}\right)$ methanolysis, propylene carbonate transesterification, urea methanolysis, oxidative carbonylation of $\mathrm{CH}_{3} \mathrm{OH}$, electrosynthesis, and direct synthesis of $\mathrm{DMC}$ from $\mathrm{CO}_{2}$ and $\mathrm{CH}_{3} \mathrm{OH}$ have been

\footnotetext{
* Corresponding author. Tel: +86-351-4041153; Fax: +86-351-4046129; E-mail: zhaoning@sxicc.ac.cn

\# Corresponding author. Tel: +86-351-4041153; Fax: +86-351-4046129; E-mail: xiaofk@sxicc.ac.cn

This work was financially supported by the Natural Science Foundation of Shanxi Province, China (201601D102006), the Science Foundation for Young Scientists of Shanxi Province, China (201701D221052), the National Natural Science Foundation of China (21776294), the Key Science and Technology Program of Shanxi Province, China (MD2014-09, MD2014-10), and the Independent Research Project of the State Key Laboratory of Coal Conversion (2018BWZ002).

DOI: S1872-2067(19)63291-2 | http://www.sciencedirect.com/science/journal/18722067 | Chin. J. Catal., Vol. 40, No. 4, April 2019
} 
developed. Among these, the direct synthesis of DMC from $\mathrm{CO}_{2}$ and $\mathrm{CH}_{3} \mathrm{OH}$ is considered as the most environment-friendly pathway due to the avoidance of highly toxic reagents such as $\mathrm{COCl}_{2}$ and $\mathrm{CO}$, the high atom utilization (83\%), and the direct utilization of greenhouse gas $\mathrm{CO}_{2}[2,4-7]$.

For the synthesis of DMC from $\mathrm{CH}_{3} \mathrm{OH}$ and $\mathrm{CO}_{2}$, many catalysts have been developed. Among the reported heterogeneous catalysts such as $\mathrm{ZrO}_{2}$ [8-10], $\mathrm{CeO}_{2}$ [11,12], $\mathrm{Ce}_{x} \mathrm{Zr}_{1-x} \mathrm{O}_{2}$ [13], $\mathrm{Fe}_{x} \mathrm{Zr}_{1-x} \mathrm{O}_{y}$ [14], $\mathrm{ZrO}_{2} / \mathrm{SBA}-15$ [15], $\mathrm{Al}_{2} \mathrm{O}_{3} / \mathrm{CeO}_{2}$ [16], $\mathrm{Ce}_{x} \mathrm{Zr}_{1-x} \mathrm{O}_{2}$ /grapheme [17], [EMIM] $\mathrm{Br} / \mathrm{Ce}_{0.5} \mathrm{Zr}_{0.5} \mathrm{O}_{2}$ [18], and $\mathrm{Cu}-\mathrm{Ni} / \mathrm{ZrO}_{2}$ [19]. Zr-based metal oxide catalysts have attracted much attention owing to their excellent stability as well as high selectivity towards DMC. However, low surface area and undeveloped porosity of the Zr-based metal oxide catalysts may limit their activity because the bulk phase of the catalyst is inaccessible and ineffective, and the number of active sites exposed on the external surface of the catalyst are insufficient [20].

Metal organic frameworks (MOFs), a class of crystalline porous materials constructed from various organic ligands and metal nodes, are promising in heterogeneous catalysis owing to their large surface area, highly developed porosity, as well as a large number of accessible active sites in the coordination-unsaturated metal nodes [21-23]. To address the disadvantages of $\mathrm{Zr}$-based metal oxide catalyst for the first time, we have previously employed trifluoroacetic acid (TFA)-modulated Zr-based metal-organic frameworks UiO-66-X as the catalysts for the direct synthesis of DMC from $\mathrm{CO}_{2}$ and $\mathrm{CH}_{3} \mathrm{OH}$, where $\mathrm{X}$ refers to the molar equivalents of TFA modulator relative to the organic linker (terephthalic acid, BDC) used in UiO-66-X synthesis. Results suggested that catalyst Ui0-66-24 showed the best catalytic activity with a DMC formation rate of $0.17 \mathrm{mmol} \mathrm{g-cat}^{-1} \mathrm{~h}^{-1}$ in the absence of a dehydrating agent. This rate is much higher than that of $\mathrm{ZrO}_{2}$ (0.03 mmol g-cat ${ }^{-1} \mathrm{~h}^{-1}$ ). Through characterization, it was found that UiO-66-24 could not only provide higher surface area ( $>1479 \mathrm{~m}^{2} \mathrm{~g}^{-1}$ ) and highly developed pore structure, but also could provide a larger number of acidic sites (hydroxyl and coordinately unsaturated $\mathrm{Zr}^{4+}$ sites) and basic sites (coordinately unsaturated $\mathrm{O}$ sites) when compared to that by $\mathrm{ZrO}_{2}$, and endowed it with a higher catalytic activity [24]. Although UiO-66-24 was a promising catalyst for the synthesis of DMC from $\mathrm{CH}_{3} \mathrm{OH}$ and $\mathrm{CO}_{2}$, its micropores with a diameter $<1.2 \mathrm{~nm}$ might be too small for the reaction between two $\mathrm{CH}_{3} \mathrm{OH}$ molecules and one $\mathrm{CO}_{2}$ molecule (accumulation diameter of two $\mathrm{CH}_{3} \mathrm{OH}$ and one $\mathrm{CO}_{2}$ molecules is about $1.3 \mathrm{~nm}$ ), indicating that the active sites located in these micropores could not be utilized for the reaction [24-26]. Therefore, in order to allow the contact of the reactants with as many active sites as possible, exploration of other Zr-based MOFs with sufficient active sites and larger pore sizes may be an effective strategy for the direct synthesis of $\mathrm{DMC}$ from $\mathrm{CO}_{2}$ and methanol.

To date, several Zr-based MOFs with different connectivities, including UiO-66 (with 12-connected $\mathrm{Zr}_{6}$ nodes), NU-1000 (with 8-connected $\mathrm{Zr}_{6}$ nodes), and MOF-808 (with 6-connected $\mathrm{Zr}_{6}$ nodes), have been reported [22,23,27]. It was suggested that the Zr-based MOFs with lower connectivity could not only provide sufficient active sites, but also larger pore sizes for the catalytic reaction $[22,23]$. Therefore, we hypothesized that MOF-808, which possesses the lowest connectivity, may be a promising candidate for the direct synthesis of $\mathrm{DMC}$ from $\mathrm{CO}_{2}$ and methanol.

Hence, in this work, a series of MOF-808-X catalysts with different metal/ligand molar ratios (molar ratio of $\mathrm{ZrOCl}_{2} \cdot 8 \mathrm{H}_{2} \mathrm{O} / \mathrm{BTC}$ from 0.5 to 5 ) were synthesized and used as catalysts for the direct synthesis of $\mathrm{DMC}$ from $\mathrm{CO}_{2}$ and $\mathrm{CH}_{3} \mathrm{OH}$ in the presence of TMM as a dehydrating agent (Eqs. 1 and 2) [18]. The effects of $\mathrm{ZrOCl}_{2} \cdot 8 \mathrm{H}_{2} \mathrm{O} / \mathrm{BTC}$ molar ratio on the physicochemical properties and catalytic activities of MOF-808-X were investigated by XRD, TEM, $\mathrm{N}_{2}$-physisorption, TGA, FT-IR, $\mathrm{NH}_{3}$-TPD, and $\mathrm{CO}_{2}$-TPD techniques. The relationship between the activities and physicochemical properties (especially the acid-base property and the micropore size) of MOF-808-X was clarified. In addition, in situ FT-IR spectroscopy was used to unravel the reaction mechanism over MOF-808-4. Finally, the effects of different reaction parameters on DMC formation and the reusability of MOF-808-X were also studied.

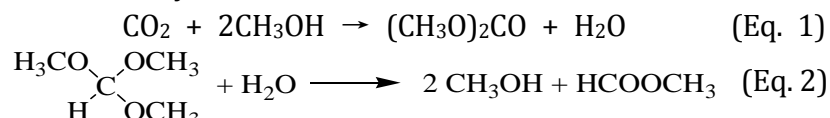

\section{Experimental}

\subsection{Materials}

Zirconium chloride $\left(\mathrm{ZrCl}_{4}, 98 \%\right)$, zirconium oxychloride octahydrate $\left(\mathrm{ZrOCl}_{2} \cdot 8 \mathrm{H}_{2} \mathrm{O}, 98 \%\right)$, terephthalic acid (BDC, 99\%), 1,3,5-benzenetricarboxylic (BTC, 99\%), and 1,1,1-trimethoxymethane (TMM, 99.5\%) were purchased from Aladdin Industrial Inc. (Shanghai, China). $\mathrm{N}, \mathrm{N}$-dimethylformamide (DMF, 98\%), $\mathrm{CH}_{3} \mathrm{OH}$ (99.8\%), benzene (99\%), and dimethyl carbonate (DMC, 99\%) were obtained from Tianli Chemical Co. (Tianjin, China). Carbon dioxide $\left(\mathrm{CO}_{2}\right.$, 99.9\%), ammonia $\left(\mathrm{NH}_{3}, 99.9 \%\right)$, and argon ( $\left.\mathrm{Ar}, 99.99 \%\right)$ were purchased from Yihong Gas Industrial Co. (Taiyuan, China). All chemicals were commercially available and used without further purification except for methanol, which was treated with activated $4 \AA$ A zeolite to remove water.

\subsection{Catalyst preparation}

MOF-808-X were synthesized by adjusting the molar ratio of metal to ligand following the method reported by Li et al. [28], with some modifications (Scheme 1). Typically, a predetermined amount of $\mathrm{ZrOCl}_{2} \cdot 8 \mathrm{H}_{2} \mathrm{O}(1.90,2.58,5.16,7.74,10.32$, and $12.91 \mathrm{~g}$ corresponding to $4,8,16,24,32$, and $40 \mathrm{mmol}$, respectively) and $1.68 \mathrm{~g}(8 \mathrm{mmol})$ of BTC (the molar ratios of $\mathrm{ZrOCl}_{2} \cdot 8 \mathrm{H}_{2} \mathrm{O} / \mathrm{BTC}$ corresponding to $0.5,1,2,3,4$, and 5 , respectively) were dissolved in DMF/formic acid (200 mL/200 mL) mixture with magnetic stirring until a clear solution was obtained. Then the solution was transferred into a $1000 \mathrm{~mL}$ glass flask and heated at $130{ }^{\circ} \mathrm{C}$ while continuously stirring for $4 \mathrm{~h}$. After naturally cooling to room temperature, the white precipitate was collected by centrifugation and washed with fresh 


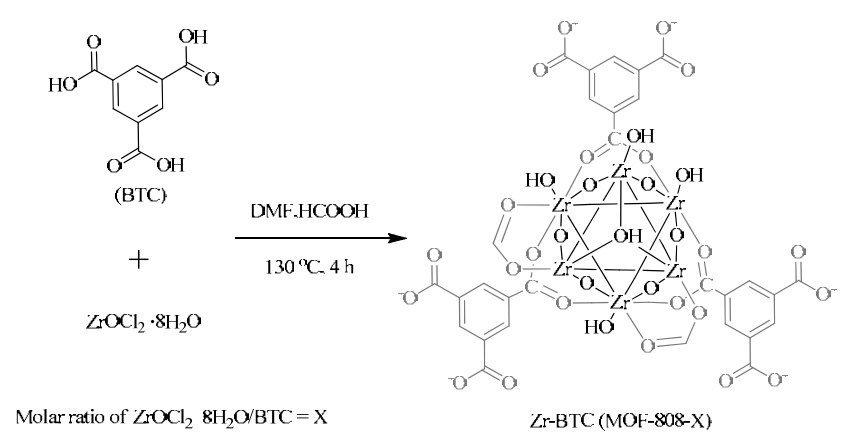

Scheme 1. Synthesis of MOF-808-X.

DMF three times, followed by double extraction with $200 \mathrm{~mL}$ of DMF for $12 \mathrm{~h}$ to remove the unreacted BTC. Thereafter, to remove the DMF molecules trapped inside the pores of the product, $\mathrm{CH}_{3} \mathrm{OH}$ was used instead of DMF and the same procedure as that of BTC removal was followed. Finally, all the purified catalysts were dried at $80{ }^{\circ} \mathrm{C}$ under vacuum for $12 \mathrm{~h}$ and The as-prepared catalysts are denoted as MOF-808-X $(\mathrm{X}=0.5,1,2$, $3,4,5)$, where $\mathrm{X}$ represents the molar ratio of $\mathrm{ZrOCl}_{2} \cdot 8 \mathrm{H}_{2} \mathrm{O} / \mathrm{BTC}$.

\subsection{Catalyst characterization}

X-ray diffraction (XRD) patterns were recorded on a Bruker D8 Advance diffractometer operated at $40 \mathrm{kV}$ and $40 \mathrm{~mA}$ with $\mathrm{Cu} \mathrm{K} \mathrm{K}_{\alpha}$ radiation $(\lambda=1.5406 \AA)$ over the $2 \theta$ range of $2^{\circ}-90^{\circ}$ and a scanning speed of $2^{\circ} \mathrm{min}^{-1}$.

The morphologies of MOF-808-X were observed with a high resolution transmission electron microscope (HRTEM, JEM-2010, JEOL, Japan) at an accelerating voltage of $200 \mathrm{kV}$.

Nitrogen sorption-desorption isotherms were measured at $-196^{\circ} \mathrm{C}$ on a Micromeritics Tristar ASAP 2020 instrument. Prior to the measurement, all the samples were degassed under vacuum at $150{ }^{\circ} \mathrm{C}$ for $12 \mathrm{~h}$. Specific surface areas of the samples were calculated using the Brunauer-Emmett-Teller (BET) equation, and pore size distributions were obtained using the Original Density Functional Theory (ODFT) method.

Thermogravimetric analysis (TGA) was carried out to estimate the composition of MOF-808-X by using a NETZSCH thermogravimetric analyzer with a heating rate of $2{ }^{\circ} \mathrm{C} \mathrm{min}-1$ from room temperature to $800{ }^{\circ} \mathrm{C}$ in air.

Fourier transform infrared (FT-IR) spectra were recorded on a Nicolet Nexus 470 FT-IR spectrometer fitted with a transmission attachment to further study the compositions of MOF-808-X.

$\mathrm{NH}_{3}$-temperature-programed desorption ( $\mathrm{NH}_{3}$-TPD) and $\mathrm{CO}_{2}$-temperature-programed desorption $\left(\mathrm{CO}_{2}\right.$-TPD) were conducted to investigate the acid-base properties of the catalysts. Prior to adsorption, the samples (30 mg, 20-40 mesh) were pretreated with argon $\left(40 \mathrm{~mL} \mathrm{~min}^{-1}\right)$ at $150{ }^{\circ} \mathrm{C}$ for $3 \mathrm{~h}$. Adsorption process was performed in $\mathrm{NH}_{3}$ or $\mathrm{CO}_{2}\left(40 \mathrm{~mL} \mathrm{~min}^{-1}\right)$ for 1 $h$ at room temperature. The physisorbed $\mathrm{NH}_{3}$ or $\mathrm{CO}_{2}$ was then flushed with argon at room temperature for $1 \mathrm{~h}$. Thereafter, the desorption process was conducted from room temperature to $700{ }^{\circ} \mathrm{C}$ with a heating rate of $10{ }^{\circ} \mathrm{C} \mathrm{min}-1$ under argon flow $(40$
$\mathrm{mL} \mathrm{min}-1$ ), and the desorbed $\mathrm{NH}_{3}$ and $\mathrm{CO}_{2}$ were continuously monitored using a BALZERS Q-Mass spectrometer with the mass signals of $m / e=17$ and 44 , respectively.

The possibly leached $\mathrm{Zr}^{4+}$ was determined by an inductively coupled plasma atomic emission spectrometer (ICP-AES, Thermo iCAP6300, Thermo Fisher, USA).

\subsection{Catalytic reaction}

The direct synthesis of DMC from $\mathrm{CO}_{2}$ and $\mathrm{CH}_{3} \mathrm{OH}$ in the presence of TMM as the dehydrating agent was carried out in an $80 \mathrm{~mL}$ Teflon-lined stainless-steel autoclave equipped with a magnetic stirrer, heating jacket and a thermocouple. Typically, $0.5 \mathrm{~g}$ of the catalyst (activated at $150^{\circ} \mathrm{C}$ for $12 \mathrm{~h}$ under vacuum before use) was introduced into the autoclave. Then a mixture of $\mathrm{CH}_{3} \mathrm{OH}$ (200 mmol) and TMM (20 to $140 \mathrm{mmol}$ ) was added into the reactor. After that, the autoclave was purged with $\mathrm{CO}_{2}$ until the desired pressure was reached. After reacting for a specific amount of time, the reactor was immediately cooled by ice-water bath and depressurized. The reaction mixture in liquid was separated by centrifugation. Products in both liquid and gas phases were analyzed using a gas chromatograph (GC) equipped with a capillary column SHIMADZU CBP/20 and a flame ionization detector (FID). For all the reactions, DMC was only detected in the liquid phase and no other by-products were detected in both liquid and gas phases. Therefore, the DMC selectivity was considered to be $100 \%$. The amount of DMC formed was determined by the internal method with benzene as the internal standard. The DMC yield and its formation rate were calculated from Eqs. 3 and 4, respectively. The turnover frequency (TOF) based on the amount of metal in various catalysts was calculated from Eq. 5 .

$$
\begin{aligned}
& \text { DMC formation rate }=\frac{\text { Amount of DMC formed }(\mathrm{mmol})}{\text { Reaction time }(\mathrm{h}) \times \text { Amount of catalyst (g) }}(\text { Eq. } 4) \\
& \text { TOF }=\frac{\text { Amount of DMC formed }(\mathrm{mmol})}{\text { Amount of metal in catalyst }\left(\mathrm{mmol} \mathrm{g-cat}{ }^{-1}\right) \times \text { Reaction time (h) }}(\text { Eq. } 5)
\end{aligned}
$$

\subsection{Reaction mechanism investigation}

The reaction mechanism for the direct synthesis of DMC from $\mathrm{CH}_{3} \mathrm{OH}$ and $\mathrm{CO}_{2}$ was investigated using the in situ FT-IR spectroscopy. Approximately $15 \mathrm{mg}$ of MOF-808-4 was pressed into a self-supporting thin wafer with a diameter of $1 \mathrm{~cm}$, which was loaded into an in situ FT-IR apparatus equipped with $\mathrm{CaF}_{2}$ windows and connected to a vacuum system. Prior to $\mathrm{CH}_{3} \mathrm{OH}$ adsorption, the catalyst disk was degassed at $150{ }^{\circ} \mathrm{C}$ until no further change in the spectra was observed. After degassing, $\mathrm{CH}_{3} \mathrm{OH}$ adsorption over the catalyst disk was carried out at 140 ${ }^{\circ} \mathrm{C}$ for an assigned time. Then, $\mathrm{CO}_{2}$ was introduced into the system to study the $\mathrm{CO}_{2}$ adsorption. A Nicolet Nexus 470 FT-IR spectrometer with a resolution of $4 \mathrm{~cm}^{-1}$ was used for recording the spectra in the range of 1000 to $4000 \mathrm{~cm}^{-1}$.

\section{Results and discussion}




\subsection{Structural and textural properties of MOF-808-X}

The structural properties of MOF-808-X were studied by XRD and TEM. It can be seen from Fig. 1a that the XRD patterns of all the catalysts synthesized using different molar ratios of $\mathrm{ZrOCl}_{2} \cdot 8 \mathrm{H}_{2} \mathrm{O} / \mathrm{BTC}$ matched well with the reported MOF-808 $[22,28]$, demonstrating the successful synthesis of MOF-808-X catalysts. Based on the peak width of $2 \theta=4.4^{\circ}$ and the Scherer equation, the crystallite sizes of MOF-808-X were calculated to be $19,22,26,53,60$, and $31 \mathrm{~nm}$, respectively. The particle size variation trend reflected by XRD was in good accordance with the results of TEM (Fig. $1 \mathrm{~b}-\mathrm{g}$ ). In addition, with the molar ratio of $\mathrm{ZrOCl}_{2} \cdot 8 \mathrm{H}_{2} \mathrm{O} / \mathrm{BTC}$ increasing from 0.5 to 4 , the peak intensity of the XRD patterns increased and the morphology of MOF-808-X gradually changed from inter-grown irregular particles for MOF-808-0.5, MOF-808-1, and MOF-808-2 to octahedral for MOF-808-3 and MOF-808-4, indicating the increased crystallinity of MOF-808-X. However, as the molar ratio of $\mathrm{ZrOCl}_{2} \cdot 8 \mathrm{H}_{2} \mathrm{O} / \mathrm{BTC}$ was further increased to 5 , the crystallinity decreased. The low crystallinity of MOF-808-0.5, MOF-808-1, and MOF-808-2 compared to MOF-808-3 and MOF-808-4 is probably attributed to the disturbance by BTC trapped in the pores of MOF-808, since the molar ratios of $\mathrm{ZrOCl}_{2} \cdot 8 \mathrm{H}_{2} \mathrm{O} / \mathrm{BTC}$ for MOF-808-0.5, -1 , and -2 synthesis were lower than that for the perfect MOF-808 synthesis (molar ratio of
$\mathrm{ZrOCl}_{2} \cdot 8 \mathrm{H}_{2} \mathrm{O} / \mathrm{BTC}=3$ ), i.e. $\mathrm{BTC}$ was redundant for the construction of perfect MOF-808. The low crystallinity of MOF-808-5 might be due to the disturbance of zirconium clusters trapped in the pores of MOF-808-5, since $\mathrm{ZrOCl}_{2} \cdot 8 \mathrm{H}_{2} \mathrm{O}$ is redundant for the perfect MOF-808 construction [29,30]. From the XRD and TEM results, it can be concluded that the crystallinity of MOF-808-X is highly dependent on the molar ratio of $\mathrm{ZrOCl}_{2} \cdot 8 \mathrm{H}_{2} \mathrm{O} / \mathrm{BTC}$, and that MOF-808-4 exhibits the best crystallinity.

$\mathrm{N}_{2}$ adsorption-desorption was performed to investigate the effect of the $\mathrm{ZrOCl}_{2} \cdot 8 \mathrm{H}_{2} \mathrm{O} / \mathrm{BTC}$ molar ratio on the textural properties of MOF-808-X. $\mathrm{N}_{2}$ adsorption isotherms presented in Fig. 2a show that MOF-808-0.5, -1, and -2 exhibit type IV isotherms with H3 hysteresis loops, while MOF-808-3, -4 , and -5 show type I isotherm. This indicates that MOF-808-0.5, -1 , and -2 possess micropores and mesopores/macropores, while the pore structures of MOF-808-3, -4 , and -5 predominantly consisted of micropores, as reflected by their pore size distributions (Fig. 2b). The mesopores/macropores with diameters in the range of 6-130 nm in MOF-808-0.5, -1, and -2, reflected by pore size distribution, are probably formed by the accumulation of particles, since the pores in this diameter range were not observed in the TEM images (insertion of Figures $1 \mathrm{~b}-\mathrm{d}$ ). Typically, the characteristic micropore size of perfect MOF-808 was $1.8 \mathrm{~nm}[22,23]$. However, from the results in Fig. 2b, it can
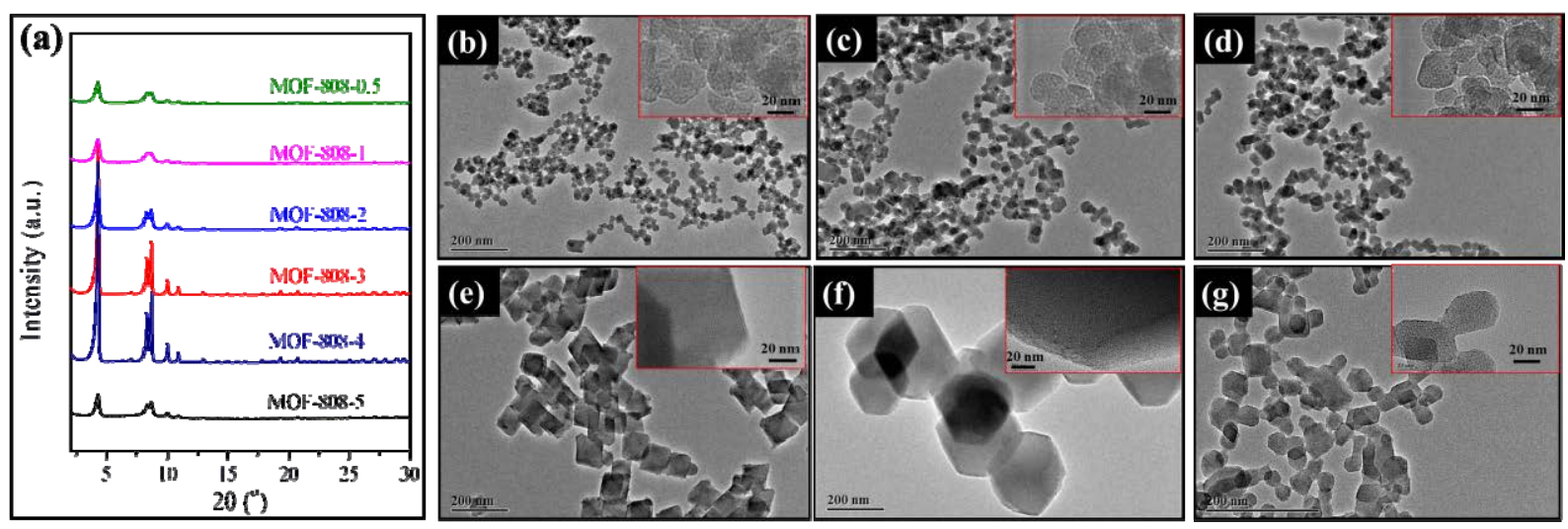

Fig. 1. (a) XRD patterns of MOF-808-X, and TEM images of (b) MOF-808-0.5, (c) MOF-808-1, (d) MOF-808-2, (e) MOF-808-3, (f) MOF-808-4, and (g) MOF-808-5.
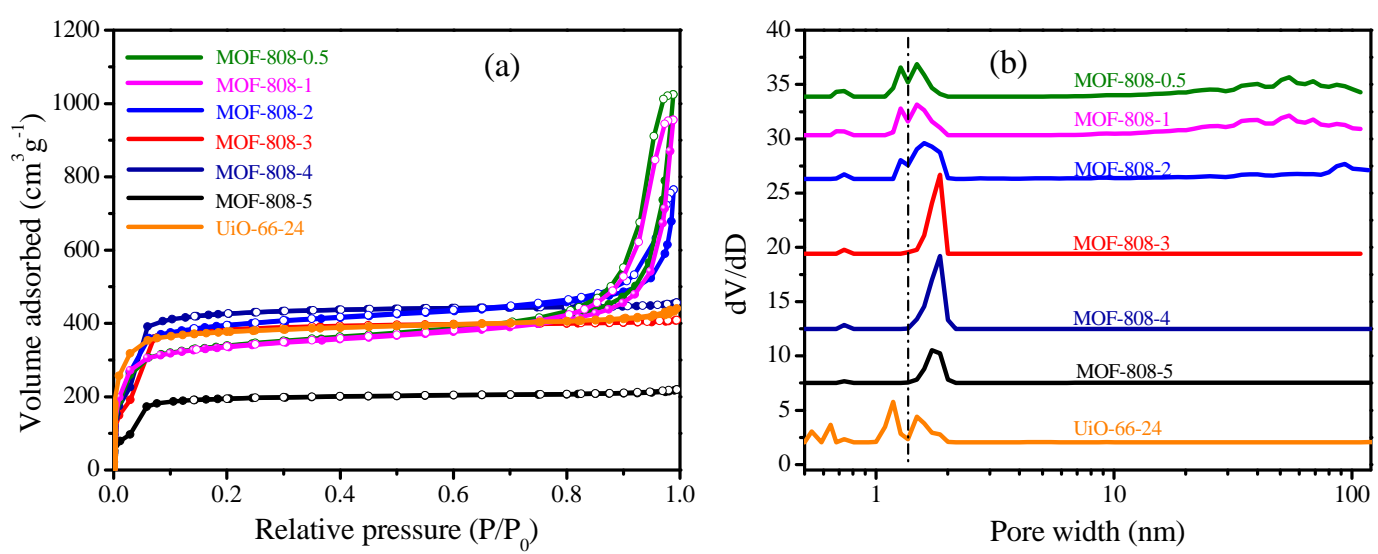

Fig. 2. (a) Nitrogen adsorption-desorption isotherms and (b) pore size distribution of various catalysts. 
Table 1

Textural properties of various catalysts.

\begin{tabular}{|c|c|c|c|c|}
\hline \multirow{2}{*}{ Catalyst } & \multirow{2}{*}{$\begin{array}{c}S_{\mathrm{BET}} \\
\left(\mathrm{m}^{2} \mathrm{~g}^{\left.-\mathrm{cat}^{-1}\right)}\right.\end{array}$} & \multirow{2}{*}{$\begin{array}{l}\text { Average } \\
\text { pore size } \\
(\mathrm{nm})\end{array}$} & \multicolumn{2}{|c|}{ Pore volume $\left(\mathrm{cm}^{3} \mathrm{~g}-\mathrm{cat}^{-1}\right)$} \\
\hline & & & Total $\left(V_{\mathrm{p}}\right)$ & Micropore $\left(V_{\text {micro }}\right)$ \\
\hline MOF-808-0.5 & 1142 & 5.5 & 1.59 & 0.34 \\
\hline MOF-808-1 & 1155 & 5.2 & 1.47 & 0.35 \\
\hline MOF-808-2 & 1290 & 3.5 & 1.18 & 0.42 \\
\hline MOF-808-3 & 1311 & 2.1 & 0.70 & 0.47 \\
\hline MOF-808-4 & 1373 & 2.0 & 0.63 & 0.51 \\
\hline MOF-808-5 & 665 & 2.0 & 0.33 & 0.23 \\
\hline UiO-66-24 [24] & 1479 & 1.8 & 0.68 & 0.48 \\
\hline
\end{tabular}

be noted that the micropores in MOF-808-0.5, -1, and -2 were mainly centered at 1.2 and $1.8 \mathrm{~nm}$. The pore with $1.2 \mathrm{~nm}$ size was probably derived from the trapping of BTC molecules in the micropores with the diameter of $1.8 \mathrm{~nm}$, since BTC for MOF-808-0.5, -1, and -2 synthesis was redundant for the perfect MOF-808 construction [29,30]. As can be seen in Fig. 2b, with the $\mathrm{ZrOCl}_{2} \cdot 8 \mathrm{H}_{2} \mathrm{O} / \mathrm{BTC}$ molar ratio gradually increasing from 0.5 to 4 , the number of the micropores centered at $1.2 \mathrm{~nm}$ decreased and finally disappeared for MOF-808-3 and MOF-808-4. Accordingly, the number of micropores centered at $1.8 \mathrm{~nm}$ increased, indicating the decrease of BTC trapped in the micropores, which probably accounts for the increase of the BET surface area $\left(S_{\mathrm{BET}}\right)$ (from $1142 \mathrm{~m}^{2} \mathrm{~g}_{\text {-cat }}{ }^{-1}$ to $1373 \mathrm{~m}^{2}$ g-cat $\left.{ }^{-1}\right)$, micropore volume $\left(V_{\text {micro}}\right)$ (from $0.34 \mathrm{~cm}^{3} \mathrm{~g} \mathrm{cat}^{-1}$ to $0.51 \mathrm{~cm}^{3} \mathrm{~g}_{\text {-cat }}-1$ ), and the micropore size of MOF-808-X, as displayed in Table 1 and Fig. 2b. However, as the $\mathrm{ZrOCl}_{2} \cdot 8 \mathrm{H}_{2} \mathrm{O} / \mathrm{BTC}$ molar ratio further increased to 5 , the $S_{\mathrm{BET}}$ and the micropore volume dramatically decreased, which might be due to the trapped zirconium clusters in the micropores of MOF-808-5, since $\mathrm{ZrOCl}_{2} \cdot 8 \mathrm{H}_{2} \mathrm{O}$ is redundant for the perfect MOF-808 construction [29,31].

By comparison with our previously reported UiO-66-24 (1479 m² g-cat $\left.^{-1}\right)$ [24], it is noted that the $S_{\mathrm{BET}}$ values of MOF-808-X were lower, but the average pore sizes were larger (Table 1 and Fig. 2b). As is well-known, although a higher surface area could provide more active sites for the catalytic reaction, a larger pore size was also desired to provide high accessibility of the active sites for the reactant.

\subsection{Composition of MOF-808-X}

TGA/DTG and FT-IR were applied to investigate the effect of $\mathrm{ZrOCl}_{2} \cdot 8 \mathrm{H}_{2} \mathrm{O} / \mathrm{BTC}$ molar ratio on the compositions of MOF-808-X. TGA/DTG profiles presented in Fig. 3 show that a minor mass-loss below $200{ }^{\circ} \mathrm{C}$ was observed due to the desorption of water and $\mathrm{CH}_{3} \mathrm{OH}$. Then, a moderate weight-loss from 200-350 ${ }^{\circ} \mathrm{C}$ was found resulting from the decomposition of $\mathrm{HCOOH}$ coordinated with $\mathrm{Zr}_{6}$ nodes. When the temperature was further raised to $350-650^{\circ} \mathrm{C}$, a sharp weight loss occurred due to the combustion of BTC coordinated with $\mathrm{Zr}_{6}$ nodes. Then BTC was completely burned out above $650{ }^{\circ} \mathrm{C}$, with $\mathrm{ZrO}_{2}$ left as the only residue $[21,32,33]$.

Based on the weight loss at $200-650^{\circ} \mathrm{C}$, the number of coordinated $\mathrm{HCOOH}$ molecules, BTC linkers, and $\mathrm{Zr}_{6}$ nodes in one MOF-808-X unit can be calculated and the chemical formula of MOF-808-X could be determined in accordance with the method reported by Shearer et al. [21,33] (Table 2). As can be seen

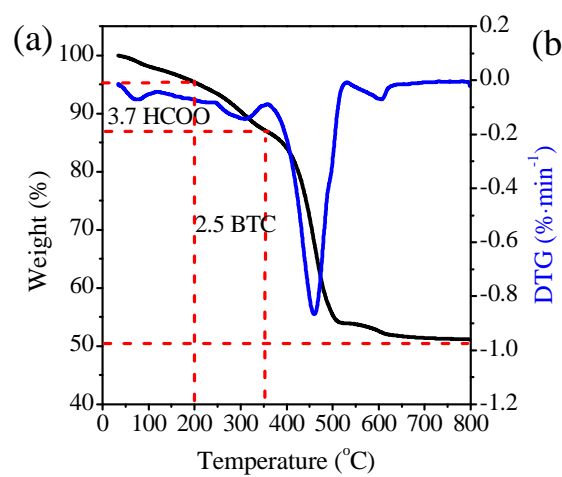

(d)

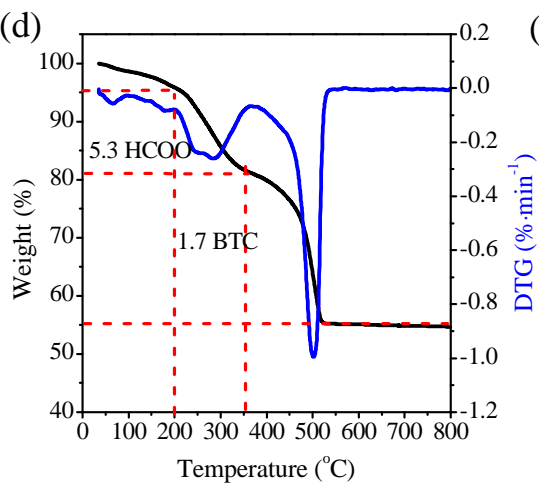

(b)

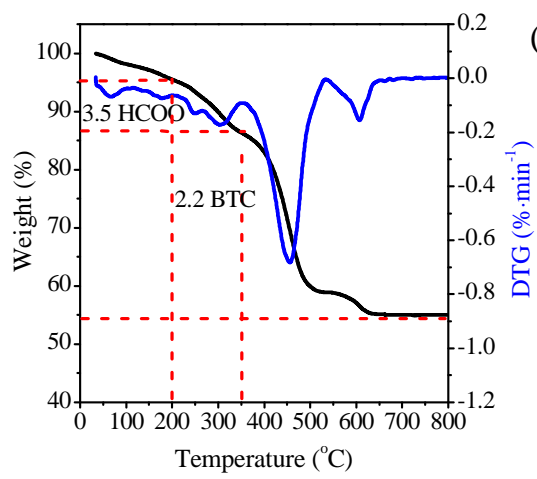

(e)

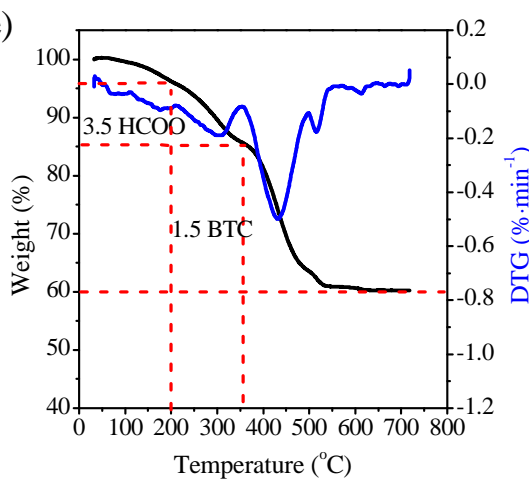

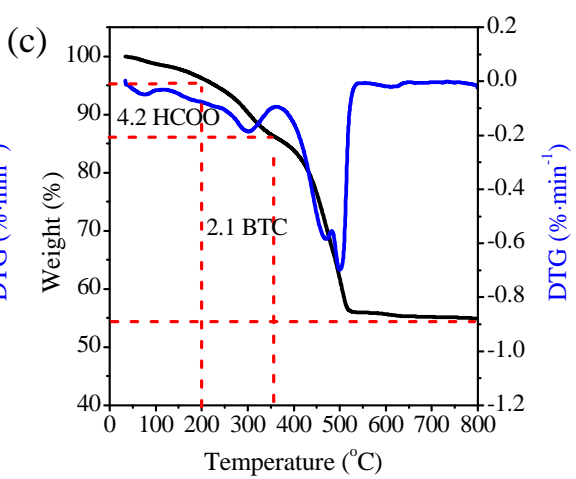

(f)

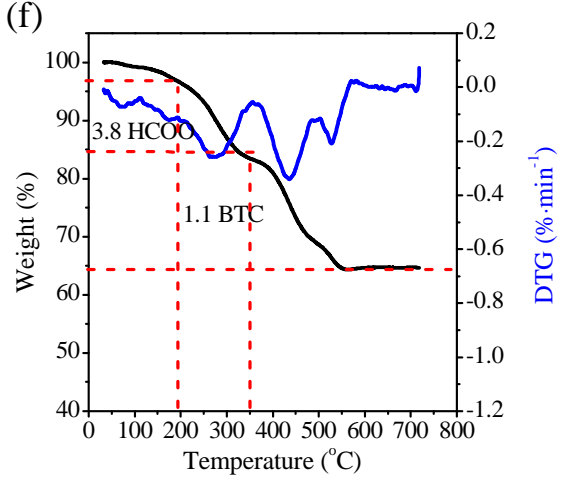

Fig. 3. TGA/DTG profiles of (a) MOF-808-0.5, (b) MOF-808-1, (c) MOF-808-2, (d) MOF-808-3, (e) MOF-808-4, and (f) MOF-808-5. 
Table 2

Composition and acid-base properties of various catalysts.

\begin{tabular}{|c|c|c|c|c|c|}
\hline \multirow{2}{*}{ Catalyst } & \multicolumn{2}{|l|}{ Composition } & \multicolumn{3}{|c|}{ Acid-base properties (mmol g-cat ${ }^{-1}$ ) } \\
\hline & Chemical formula & Linker $/ \mathrm{Zr}_{6}$ & Number of acidic sites & Number of basic sites & Total \\
\hline MOF-808-0.5 & {$\left[\mathrm{Zr}_{6} \mathrm{O}_{4}(\mathrm{OH})_{4}\right](\mathrm{BTC})_{2.5}(\mathrm{HCOO})_{3.7}$} & 2.5 & 2.8 & 1.2 & 4.0 \\
\hline MOF-808-1 & {$\left[\mathrm{Zr}_{6} \mathrm{O}_{4}(\mathrm{OH})_{4}\right](\mathrm{BTC})_{2.2}(\mathrm{HCOO})_{3.5}$} & 2.2 & 3.3 & 1.7 & 5.0 \\
\hline MOF-808-2 & {$\left[\mathrm{Zr}_{6} \mathrm{O}_{4}(\mathrm{OH})_{4}\right](\mathrm{BTC})_{2.1}(\mathrm{HCOO})_{4.2}$} & 2.1 & 3.6 & 2.2 & 5.8 \\
\hline MOF-808-3 & {$\left[\mathrm{Zr}_{6} \mathrm{O}_{4}(\mathrm{OH})_{4}\right](\mathrm{BTC})_{1.7}(\mathrm{HCOO})_{5.3}$} & 1.7 & 4.8 & 2.9 & 7.7 \\
\hline MOF-808-4 & {$\left[\mathrm{Zr}_{6} \mathrm{O}_{4}(\mathrm{OH})_{4}\right](\mathrm{BTC})_{1.5}(\mathrm{HCOO})_{3.5}$} & 1.5 & 5.2 & 3.1 & 8.3 \\
\hline MOF-808-5 & {$\left[\mathrm{Zr}_{6} \mathrm{O}_{4}(\mathrm{OH})_{4}\right](\mathrm{BTC})_{1.1}(\mathrm{HCOO})_{3.8}$} & 1.1 & 3.5 & 2.0 & 5.5 \\
\hline Perfect MOF-808 & {$\left[\mathrm{Zr}_{6} \mathrm{O}_{4}(\mathrm{OH})_{4}\right](\mathrm{BTC})_{2.0}(\mathrm{HCOO})_{6.0}$} & 2.0 & - & - & - \\
\hline UiO-66-24 [24] & {$\left[\mathrm{Zr}_{6} \mathrm{O}_{4}(\mathrm{OH})_{4}\right](\mathrm{BDC})_{4.0}\left(\mathrm{CF}_{3} \mathrm{COO}\right)_{1.7}$} & 4.0 & 4.6 & 5.2 & 9.8 \\
\hline
\end{tabular}

from Table 2, with the increasing $\mathrm{ZrOCl}_{2} \cdot 8 \mathrm{H}_{2} \mathrm{O} / \mathrm{BTC}$ molar ratio, the molar ratio of linker $/ \mathrm{Zr}_{6}$ gradually decreased from 2.5 for MOF-808-0.5 to 1.1 for MOF-808-5, which is also be reflected in the FT-IR spectra of MOF-808-X (Fig. 4), i.e. as the $\mathrm{ZrOCl}_{2} \cdot 8 \mathrm{H}_{2} \mathrm{O} / \mathrm{BTC}$ molar ratio increased, the bands at 1617 , 1572,1385 , and $760 \mathrm{~cm}^{-1}$ belonging to BTC (labeled with blue arrow) decreased [29,34], and the bands at 714 and $660 \mathrm{~cm}^{-1}$ attributed to $\mathrm{Zr}-\mathrm{O}$ bond in $\mathrm{Zr}_{6}$ nodes (labeled with purple arrow) increased [35], further indicating the decrease in linker/Zr 6 node molar ratio. In addition, it is noted from Table 2 that higher linker/Zr 6 molar ratios were observed in MOF-808-0.5, - 1 , and - 2 when compared to that in the perfect MOF-808 (linker $/ \mathrm{Zr}_{6}$ molar ratio $=2.0$ ), indicating the presence of unreacted BTC trapped in MOF-808-X, which was in good agreement with the $\mathrm{N}_{2}$ adsorption-desorption results. The bands at $1715 \mathrm{~cm}^{-1}$ corresponding to the uncoordinated -COOH of free BTC in the FT-IR spectra of MOF-808-0.5, -1, and -2 also demonstrated the presence of unreacted BTC trapped in these samples $[29,36]$. In contrast, for MOF-808-3, -4 , and -5 , since BTC was insufficient for the construction of perfect MOF-808, the linker/Zr6 node molar ratio $(<2.0)$ was lower than that in perfect MOF-808, indicating that almost no BTC was trapped in the micropores of MOF-808-3, -4, and -5 . Therefore, the dramatic decrease in $S_{\mathrm{BET}}$ and the micropore volumes of MOF-808-5 could be attributed to the trapped zirconium clusters in the micropores.

To summarize, the $\mathrm{N}_{2}$ adsorption-desorption, TGA/DTG, and

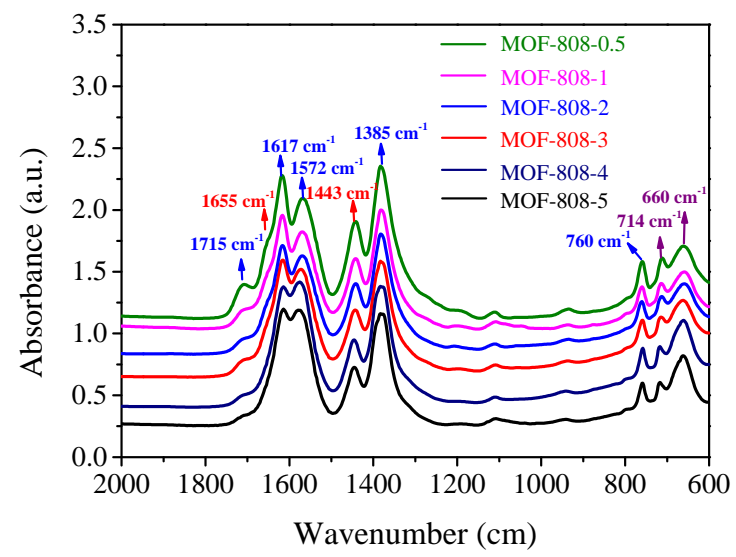

Fig. 4. FT-IR spectra of MOF-808-X.
FT-IR results indicated that with the $\mathrm{ZrOCl}_{2} \cdot 8 \mathrm{H}_{2} \mathrm{O} / \mathrm{BTC}$ molar ratio increasing from 0.5 to 4 , the amount of BTC trapped in the micropores of MOF-808-X decreased, leading to the increased surface area and micropore size. Accordingly, the molar ratio of linker/Zr 6 node of MOF-808-X decreased, i.e. the number of $\mathrm{Zr}_{6}$ nodes per unit weight of catalyst for the direct synthesis of DMC from $\mathrm{CO}_{2}$ and $\mathrm{CH}_{3} \mathrm{OH}$ increased. However, further increasing the $\mathrm{ZrOCl}_{2} \cdot 8 \mathrm{H}_{2} \mathrm{O} / \mathrm{BTC}$ molar ratio to 5 resulted in the presence of redundant zirconium clusters trapped in the micropores and the significant decrease of BET surface area and micropore volume of MOF-808-5. It should be noted that although unreacted BTC or the redundant zirconium clusters in MOF-808-X could be partly removed by DMF washing, BTC or redundant zirconium clusters trapped in the micropores of MOF-808-5 were difficult to be completely removed [37]. Therefore, the results implied that a proper molar ratio of $\mathrm{ZrOCl}_{2} \cdot 8 \mathrm{H}_{2} \mathrm{O} / \mathrm{BTC}$ was fairly important to reduce the redundant BTC or zirconium clusters trapped in the micropores of MOF-808-X. Additionally, it was noted from TGA profile that the weight of residual $\mathrm{ZrO}_{2}$ in MOF-808-X (50\% 64\%) was higher than that in UiO-66-24 (41\%) [24], suggesting that MOF-808-X could provide more $\mathrm{Zr}_{6}$ nodes than UiO-66-24 for this reaction.

\subsection{Acid-base properties of MOF-808-X}

It was earlier reported that the acid-base properties are crucial for the direct synthesis of DMC from $\mathrm{CO}_{2}$ and $\mathrm{CH}_{3} \mathrm{OH}$ $[9,14,38]$. Thus, $\mathrm{NH}_{3}$-TPD and $\mathrm{CO}_{2}$-TPD were carried out to detect the acid and base properties, respectively, of MOF-808-X. For the $\mathrm{NH}_{3}$-TPD profiles of MOF-808-X (Fig. 5a), $\mathrm{NH}_{3}$ desorption peaks below $250{ }^{\circ} \mathrm{C}$ were observed, which can be attributed to the weak to moderate acidic sites related to the hydroxyl (Brönsted acidic site) and the exposed $\mathrm{Zr}^{4+}$ (Lewis acidic acid) in $\mathrm{Zr}_{6}$ nodes $[24,27,39,40]$. Unfortunately, due to the perturbation of $\mathrm{BTC}$ and $\mathrm{HCOOH}$ ligands, the Brönsted and Lewis acidic sites in MOF-808-X were not identified by pyridine FT-IR (Fig. S2). Based on the area of the $\mathrm{NH}_{3}$ desorption profiles, the corresponding number of acidic sites in MOF-808-X is calculated and listed in Table 2. It is found that as the molar ratio of $\mathrm{ZrOCl}_{2} \cdot 8 \mathrm{H}_{2} \mathrm{O} / \mathrm{BTC}$ increased, the number of acidic sites significantly increased from 2.8 mmol g-cat ${ }^{-1}$ for MOF-808-0.5 to 5.2 mmol g-cat ${ }^{-1}$ for MOF-808-4. As indicated by the TGA/DTG 

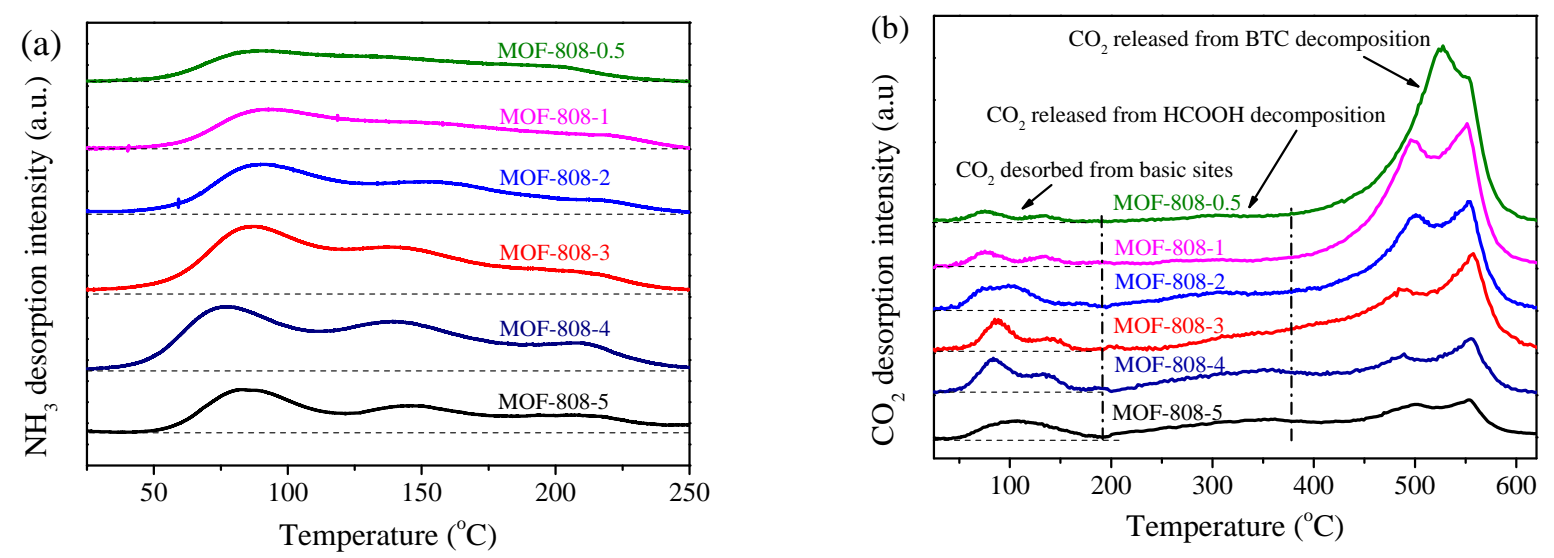

Fig. 5. (a) $\mathrm{NH}_{3}-\mathrm{TPD}$ and (b) $\mathrm{CO}_{2}$-TPD profiles of MOF-808-X.

results, the increased number of acidic sites is probably due to the increased number of $\mathrm{Zr}_{6}$ nodes in MOF-808-X [22,23,27]. However, as the molar ratio of $\mathrm{ZrOCl}_{2} \cdot 8 \mathrm{H}_{2} \mathrm{O} / \mathrm{BTC}$ further increased to 5 , the number of acidic sites decreased to $3.5 \mathrm{mmol}$ g-cat $^{-1}$, even though MOF-808-5 contained more $\mathrm{Zr}$ as indicated by the TGA/DTG results. This is probably because the redundant zirconium clusters trapped in the micropores decreased the specific surface area of MOF-808-5, which in turn inhibited the exposure of the acidic sites.

In the $\mathrm{CO}_{2}$-TPD profiles of MOF-808-X (Fig. 5b), three peaks can be identified. The peak located at 25 to $200{ }^{\circ} \mathrm{C}$ can be attributed to $\mathrm{CO}_{2}$ desorbed from the weak and moderately basic sites related to unsaturated $\mathrm{O}^{2-}$ anion of $\mathrm{Zr}-\mathrm{O}-\mathrm{Zr}$ or $\mathrm{Zr}-\mathrm{O}^{-}$in $\mathrm{Z}_{6}$ nodes [41-44]. The peaks located at 200 to $350^{\circ} \mathrm{C}$ and 350 to $650{ }^{\circ} \mathrm{C}$ can be assigned to $\mathrm{CO}_{2}$ released from the decomposition of $\mathrm{HCOOH}$ and BTC linker, respectively, as confirmed by the results of TGA/DTG and the control test in which a similar peak was observed in the TPD profile of MOF-808-4 without $\mathrm{CO}_{2}$ adsorption (Fig. S3). Based on the area of $\mathrm{CO}_{2}$ desorption peaks between 25 to $200{ }^{\circ} \mathrm{C}$, the number of basic sites in MOF-808-X is calculated and listed in Table 2 . It is found that the number of basic sites in MOF-808-X increased as the $\mathrm{ZrOCl}_{2} \cdot 8 \mathrm{H}_{2} \mathrm{O} / \mathrm{BTC}$ molar ratio increased from 0.5 to 4 , which might be due to the increased number of $\mathrm{Zr}_{6}$ nodes in MOF-808-X, as indicated by TGA/DTG $[22,23,27]$. As the molar ratio of $\mathrm{ZrOCl}_{2} \cdot 8 \mathrm{H}_{2} \mathrm{O} / \mathrm{BTC}$ further increased to 5 , the number of basic sites decreased to $2.0 \mathrm{mmol} \mathrm{g}$-cat $^{-1}$ due to the decrease in specific surface area that inhibited the exposure of the basic sites.

When compared to our previously reported UiO-66-24 [24], although MOF-808-X contains more $\mathrm{Zr}_{6}$ nodes and the connectivity of $\mathrm{Zr}_{6}$ nodes is lower, the number of acidic-basic sites in it is lower (Table 2), which might result from the partial coordination of formate ions ( $\mathrm{HCOO}^{-}$) to the unconnected sites of $\mathrm{Zr}_{6}$ nodes in MOF-808-X, as shown in Scheme 1 [22].

\subsection{Catalytic performance}

\subsubsection{Catalytic activity tests}

Catalytic activities of MOF-808-X for the direct synthesis of DMC from $\mathrm{CO}_{2}$ and $\mathrm{CH}_{3} \mathrm{OH}$ were evaluated by batch reaction and the results are summarized in Table 3. It is well known that the synthesis of DMC from $\mathrm{CO}_{2}$ and $\mathrm{CH}_{3} \mathrm{OH}$ was limited by a thermodynamic equilibrium $[45,46]$. Therefore, trimethoxyl methane (TMM) was used as the dehydrating agent to shift the reaction towards the direction of DMC formation by the removal of by-product, water [6,47]. As illustrated in Table 3, the addition of TMM significantly increased the DMC yield from $0.12 \%$ (Entry 7) to $3.28 \%$ (Entry 5) over MOF-808-4. As the formation of $\mathrm{DMC}$ from TMM and $\mathrm{CO}_{2}$ (Eq. 6) is also thermodynamically favorable [18], a control test without $\mathrm{CH}_{3} \mathrm{OH}$ was carried out to check whether DMC could be formed from the reaction of TMM and $\mathrm{CO}_{2}$. The result shows that only $0.35 \%$ (Entry 8) of DMC was formed from the reaction of TMM and $\mathrm{CO}_{2}$, indicating that TMM worked as a dehydrating agent instead of a reactant, which was in agreement with the results of Zhang et al. [18] and Saha et al. [17]. The effect of MOF-808-X catalyst on the dehydrating process (Eq. 2) was also investigated. The result indicated that the reaction rate between TMM and $\mathrm{H}_{2} \mathrm{O}$ without the catalyst was almost identical to that in the

Table 3

Catalytic activity of various catalysts.

\begin{tabular}{|c|c|c|c|c|c|c|}
\hline Entry & Catalyst & $\begin{array}{c}\mathrm{CH}_{3} \mathrm{OH} \\
(\mathrm{mmol})\end{array}$ & $\begin{array}{c}\text { TMM } \\
\text { (mmol) }\end{array}$ & $\begin{array}{c}\text { DMC } \\
\text { yield } \\
(\%)\end{array}$ & $\begin{array}{l}\text { DMC formation } \\
\text { rate }\left(\mathrm{mmol}^{-1}\right. \\
\left.\text { g-cat }^{-1} \mathrm{~h}^{-1}\right)\end{array}$ & $\begin{array}{l}\text { TOF } \\
\left(\mathrm{h}^{-1}\right)\end{array}$ \\
\hline 1 & MOF-808-0.5 & 200 & 100 & 1.50 & 0.75 & 0.18 \\
\hline 2 & MOF-808-1 & 200 & 100 & 2.10 & 1.05 & 0.24 \\
\hline 3 & MOF-808-2 & 200 & 100 & 2.80 & 1.40 & 0.32 \\
\hline 4 & MOF-808-3 & 200 & 100 & 3.16 & 1.58 & 0.33 \\
\hline 5 & MOF-808-4 & 200 & 100 & 3.28 & 1.64 & 0.34 \\
\hline 6 & MOF-808-5 & 200 & 100 & 2.44 & 1.22 & 0.23 \\
\hline 7 & MOF-808-4 & 200 & 0 & 0.12 & 0.06 & 0.01 \\
\hline 8 & MOF-808-4 & 0 & 100 & $0.35^{\mathrm{a}}$ & 0.17 & 0.04 \\
\hline 9 & UiO-66-24 & 200 & 100 & 2.14 & 1.07 & 0.31 \\
\hline 10 & $\mathrm{ZrO}_{2} \mathrm{~b}$ & 200 & 100 & 0.82 & 0.41 & 0.05 \\
\hline 11 & $\mathrm{CeO}_{2}{ }^{\mathrm{b}}$ & 200 & 100 & 0.88 & 0.44 & 0.08 \\
\hline 12 & None & 200 & 100 & 0 & 0 & - \\
\hline
\end{tabular}

Reaction conditions: $140{ }^{\circ} \mathrm{C} ; 4 \mathrm{~h} ; \mathrm{CO}_{2}$ pressure: $12 \mathrm{MPa}$; catalyst weight: $0.5 \mathrm{~g}$; reactor volume: $80 \mathrm{~mL}$.

a DMC yield for the reaction between $\mathrm{CO}_{2}$ and TMM is defined as $Y_{\mathrm{DMC}}=$ Amount of DMC formed (mmol)/Amount of TMM added (mmol) $\times$ $100 \%$.

${ }^{\mathrm{b}}$ Preparation method, XRD patterns, and SEM images of $\mathrm{ZrO}_{2}$ and $\mathrm{CeO}_{2}$ are presented in Supporting Information (S1). 
presence of MOF-808-X, indicating the negligible effect of MOF-808-X in the dehydrating process. Additionally, it should be noted that although TMM promoted the reaction through water removal, the reaction did not occur in the absence of catalyst (Entry 12), confirming that the reaction between $\mathrm{CO}_{2}$ and $\mathrm{CH}_{3} \mathrm{OH}$ proceeded catalytically.

$$
\underset{\mathrm{H}^{-}}{\mathrm{H}^{\mathrm{C}} \mathrm{OCH}_{3}} \mathrm{OCH}_{3}+\mathrm{CO}_{2} \longrightarrow\left(\mathrm{CH}_{3} \mathrm{O}\right)_{2} \mathrm{CO}+\mathrm{HCOOCH}_{3}
$$

To compare the catalytic activities of MOF-808-X, the DMC formation rates as well as the turnover frequencies (TOFs), which represent the number of DMC molecules formed based on the amount of metal present in various catalysts (the amount of metal in various catalysts is presented in Table S1), were calculated at a reaction time of $4 \mathrm{~h}$, when the reaction was within kinetic region (Fig. 8d). As illustrated in Table 3, when the molar ratio of $\mathrm{ZrOCl}_{2} \cdot 8 \mathrm{H}_{2} \mathrm{O} / \mathrm{BTC}$ gradually increased from 0.5 to 4 , the DMC formation rate gradually increased from 0.75 mmol g-cat ${ }^{-1} \mathrm{~h}^{-1}$ for MOF-808-0.5 (Entry 1) to $1.64 \mathrm{mmol}$ g-cat ${ }^{-1} \mathrm{~h}^{-1}$ for MOF-808-4 (Entry 5), while the TOF gradually increased from $0.18 \mathrm{~h}^{-1}$ to $0.34 \mathrm{~h}^{-1}$. As the molar ratio of $\mathrm{ZrOCl}_{2} \cdot 8 \mathrm{H}_{2} \mathrm{O} / \mathrm{BTC}$ further increased to 5 , the DMC formation rate and TOF decreased to $1.22 \mathrm{mmol} \mathrm{g-cat}^{-1} \mathrm{~h}^{-1}$ and $0.23 \mathrm{~h}^{-1}$, respectively (Entry 6).

According to the reported mechanism for DMC synthesis, both the acidic and basic sites play important roles in the reaction of $\mathrm{CO}_{2}$ and methanol; $\mathrm{CH}_{3} \mathrm{OH}$ is activated to methyl species and methoxy species on the acidic and basic sites, respectively. Methoxy carbonate anion is then formed by the reaction of methoxy species with $\mathrm{CO}_{2}$ adsorbed on the basic sites. Methoxy carbonate anion further reacts with methyl cation to produce DMC $[9,38,48]$. Therefore, the catalytic activity of MOF-808-X is probably highly dependent on the number of acidic and basic sites. The relationship between the number of acidic and basic sites and the DMC formation rates over MOF-808-X are presented in Fig. 6. It could be clearly seen that the DMC formation rates were basically in accordance with the order of the number of acidic and basic sites on MOF-808-X, and MOF-808-4, with the largest number of acidic and basic sites, exhibited the best activity, indicating that the higher number of acidic and basic sites are favorable for enhancing the catalytic performance, which is consistent with our previous results $[14,15,24]$ and those reported by Tomishige et al. [9] and Lee et al. [49-51].

In addition, from the $\mathrm{N}_{2}$ adsorption-desorption results, it is found that as the $\mathrm{ZrOCl}_{2} \cdot 8 \mathrm{H}_{2} \mathrm{O} / \mathrm{BTC}$ molar ratio increased from 0.5 to 4 , BTC trapped in the micropores decreased. Consequently, the volume of micropores with a diameter of $1.8 \mathrm{~nm}$ and the average micropore size of MOF-808-X increased, which may be favorable for the enhancement of the catalytic activity of MOF-808-X since larger miropore size could provide higher accessibility for the reactant to the active sites located in the micropores [14,43,52]. However, for MOF-808-5, the average pore size of which was similar to MOF-808-4, the activity was lower than that of MOF-808-4. This is probably because the redundant zirconium clusters trapped in the micropores of MOF-808-5 dramatically decreased its specific surface area and thus inhibited the exposure of the acidic-basic sites.

Considering that the structure of MOF-808-X with lower crystallinity might not be stable during the reaction, the catalytic activity of MOF-808-X may be affected. Hence, all the MOF-808-X catalysts, after activity assessment, were recycled and characterized by XRD. Results show that the structures of all the MOF-808-X after reacting for $4 \mathrm{~h}$ were well retained (Fig. S4), indicating that the different activities of MOF-808-X were mainly because of the variation in their physiochemical properties resulting from the $\mathrm{ZrOCl}_{2} \cdot 8 \mathrm{H}_{2} \mathrm{O} / \mathrm{BTC}$ regulation.

Furthermore, the best performed MOF-808-4 catalyst was compared with our previously reported $\mathrm{Zr}$-based MOF catalyst UiO-66-24 under the same reaction conditions [24]. It is noted that UiO-66-24 with higher surface area and larger number of acidic-basic sites showed a lower catalytic activity when compared to MOF-808-4, probably due to the presence of smaller micropores in UiO-66-24, which make the surface area and active sites not fully utilizable in the reaction. This strongly suggests that in spite of the lower surface area and the less number of active sites, the larger micropore size plays an important role in determining the higher catalytic activity of MOF-808-4.

The activity of MOF-808-4 was also compared with monolithic $\mathrm{ZrO}_{2}$ and spindle-like $\mathrm{CeO}_{2}$ with cubic fluorite structure, since the monolithic $\mathrm{ZrO}_{2}$ [10] and spindle-like $\mathrm{CeO}_{2}$ [12] catalysts showed superior activity among metal oxide catalysts. However, the activity of monolithic $\mathrm{ZrO}_{2}$ and spindle-like $\mathrm{CeO}_{2}$ prepared in this work (detailed synthetic procedures and characterization are presented in S1 in Supporting Information) was much lower than that of MOF-808-4 (Entries 9 and 10). These results allow us to conclude that MOF-808-4 could be a good candidate for the direct synthesis of DMC from
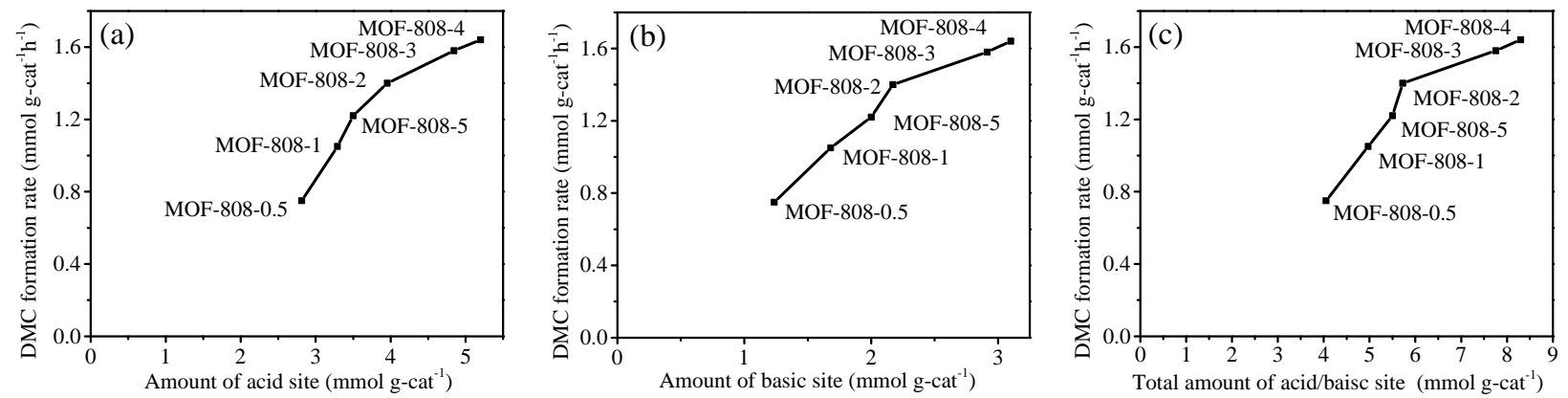

Fig. 6. Relationship between the DMC formation rate and (a) the number of acidic sites, (b) the number of basic sites, and (c) the total number of acidic and basic sites. 
$\mathrm{CO}_{2}$ and $\mathrm{CH}_{3} \mathrm{OH}$.

\subsubsection{Possible reaction mechanism}

The possible reaction mechanism for DMC synthesis over MOF-808-4 was investigated by in situ FT-IR spectroscopy (Fig. 7). Prior to $\mathrm{CH}_{3} \mathrm{OH}$ adsorption, MOF-808-4 catalyst was activated at $150{ }^{\circ} \mathrm{C}$ under vacuum until the spectra remained almost identical. As seen in Fig. 7a, the bands at 2931, 2820, 1142 , and $1037 \mathrm{~cm}^{-1}$ appeared and increased after the exposure to $\mathrm{CH}_{3} \mathrm{OH}$ at $140{ }^{\circ} \mathrm{C}$. The bands at 2931 and $2820 \mathrm{~cm}^{-1}$ are associated with $\mathrm{C}-\mathrm{H}$ stretching vibrations of terminal $\left(\mathrm{t}-\mathrm{OCH}_{3}\right.$, i.e. $\left.\mathrm{Zr}-\mathrm{OCH}_{3}\right)$ and bridged (b-OCH , i.e. $\left.\mathrm{Zr}-\left(\mathrm{OCH}_{3}\right)-\mathrm{Zr}\right)$ methoxy species, respectively. The bands at 1142 and $1037 \mathrm{~cm}^{-1}$ can be assigned to the $\mathrm{C}-\mathrm{O}$ bending vibrations of terminal $\left(\mathrm{Zr}-\mathrm{OCH}_{3}\right)$ and bridged $\left(\mathrm{Zr}-\left(\mathrm{OCH}_{3}\right)-\mathrm{Zr}\right)$ methoxy species $[10,38,48,53,54]$, respectively.

After introducing $\mathrm{CO}_{2}$ to the $\mathrm{CH}_{3} \mathrm{OH}$-pre-adsorbed MOF-808-4, the intensity of the bands related to $\mathrm{Zr}-\mathrm{OCH}_{3}$ and $\mathrm{Zr}-\left(\mathrm{OCH}_{3}\right)-\mathrm{Zr}$ gradually decreased (Fig. $\left.7 \mathrm{~b}\right)$. The decrease in intensity of $\mathrm{Zr}-\mathrm{OCH}_{3}$ probably resulted from the insertion of $\mathrm{CO}_{2}$ into $\mathrm{Zr}-\mathrm{OCH}_{3}$ resulting in the formation of intermediate $\mathrm{Zr}-\mathrm{OCOOCH}_{3}$, while the decrease in intensity of $\mathrm{Zr}-\left(\mathrm{OCH}_{3}\right)-\mathrm{Zr}$ is probably due to the reaction between $\mathrm{Zr}-\mathrm{OCOOCH}_{3}$ and the methyl group in $\mathrm{Zr}-\left(\mathrm{O}-\mathrm{CH}_{3}\right)-\mathrm{Zr}$ to form $\mathrm{DMC}[11,16,38]$. Unfortunately, the evolution of the bands corresponding to the possible intermediates $\mathrm{Zr}-\mathrm{OCOOCH}_{3}$ located between $1000-2000 \mathrm{~cm}^{-1}[38,48,53]$ were not identified due to the perturbation of BTC and $\mathrm{HCOOH}$ ligands in the FT-IR spectra (Fig. S5).
Based on the results of in situ FT-IR, a possible reaction mechanism over MOF-808-4 is inferred as follows (Scheme 2). (1) Adsorbed $\mathrm{CH}_{3} \mathrm{OH}$ initially bonds to the Lewis acidic sites (exposed $\mathrm{Zr}^{4+}$ ) of $\mathrm{Zr}_{6}$ node in MOF-808-4 to form $\mathrm{Zr}-\mathrm{OCH}_{3}$ and releases $\mathrm{H}$ atom. The $\mathrm{H}$ atom then reacts rapidly with the terminal hydroxyl $(\mathrm{Zr}-\mathrm{OH})$ to form $\mathrm{H}_{2} \mathrm{O}$. The generated $\mathrm{H}_{2} \mathrm{O}$ could coordinate with the exposed $\mathrm{Zr}^{4+}$ to form $\mathrm{Zr}-\mathrm{OH}_{2}$, as indicated by the increase in intensity of the hydroxyl group of $\mathrm{Zr}_{6}$ node (broad band at 3700-3500 $\mathrm{cm}^{-1}$ ) during $\mathrm{CH}_{3} \mathrm{OH}$ adsorption (Fig. S5a) [32]. In the actual reaction, the formed water could be removed by reacting with TMM (Eq. 6). In addition, $\mathrm{CH}_{3} \mathrm{OH}$ can also be activated into methyl cation $\left(\mathrm{CH}_{3}{ }^{+}\right)$by the acidic sites $\left(\mathrm{Zr}^{4+}\right)$ of $\mathrm{Zr}_{6}$ node, the formed $\mathrm{CH}_{3}{ }^{+}$could be then adsorbed on the basic site (unsaturated $\mathrm{O}^{2-}$ in $\mathrm{Zr}-\mathrm{O}-\mathrm{Zr}$ or $\mathrm{Zr}^{-} \mathrm{O}^{-}$) of $\mathrm{Zr}_{6}$ node to form the bridged methoxy $\left(\mathrm{Zr}-\left(\mathrm{OCH}_{3}\right)-\mathrm{Zr}\right)$. Accordingly, the hydroxyl dissociated from $\mathrm{CH}_{3} \mathrm{OH}$ could adsorb on the acidic site (exposed $\mathrm{Zr}^{4+}$ ) to form the terminal hydroxyl $(\mathrm{Zr}-\mathrm{OH})$. (2) Upon exposure to $\mathrm{CO}_{2}$, the adsorbed $\mathrm{CO}_{2}$ on the basic sites of $\mathrm{Zr}_{6}$ nodes in MOF-808-4 inserts into $\mathrm{Zr}-\mathrm{OCH}_{3}$ to form the intermediate $\mathrm{Zr}-\mathrm{OCOOCH}_{3}$. (3) Finally, the generated $\mathrm{Zr}-\mathrm{OCOOCH} 3$ reacts with $\mathrm{CH}_{3}{ }^{+}$released from $\mathrm{Zr}-\left(\mathrm{OCH}_{3}\right)-\mathrm{Zr}$ to form DMC.

It should be noted that $\mathrm{CO}_{2}$ may also first interact with the catalyst in the DMC formation procedure. According to the reaction mechanism reported by Bell et al. [38] and Inumaru et al. [10], $\mathrm{CO}_{2}$ can be activated into a bidentate bicarbonate species (b- $\mathrm{HCO}_{3}-\mathrm{Zr}$ ) and a bidentate carbonate species (b-CO $-\mathrm{Zr}$ ). The b- $\mathrm{HCO}_{3}-\mathrm{Zr}$ is active which could react with $\mathrm{CH}_{3} \mathrm{OH}$ to form methyl carbonate intermediate. However, formation of the methyl
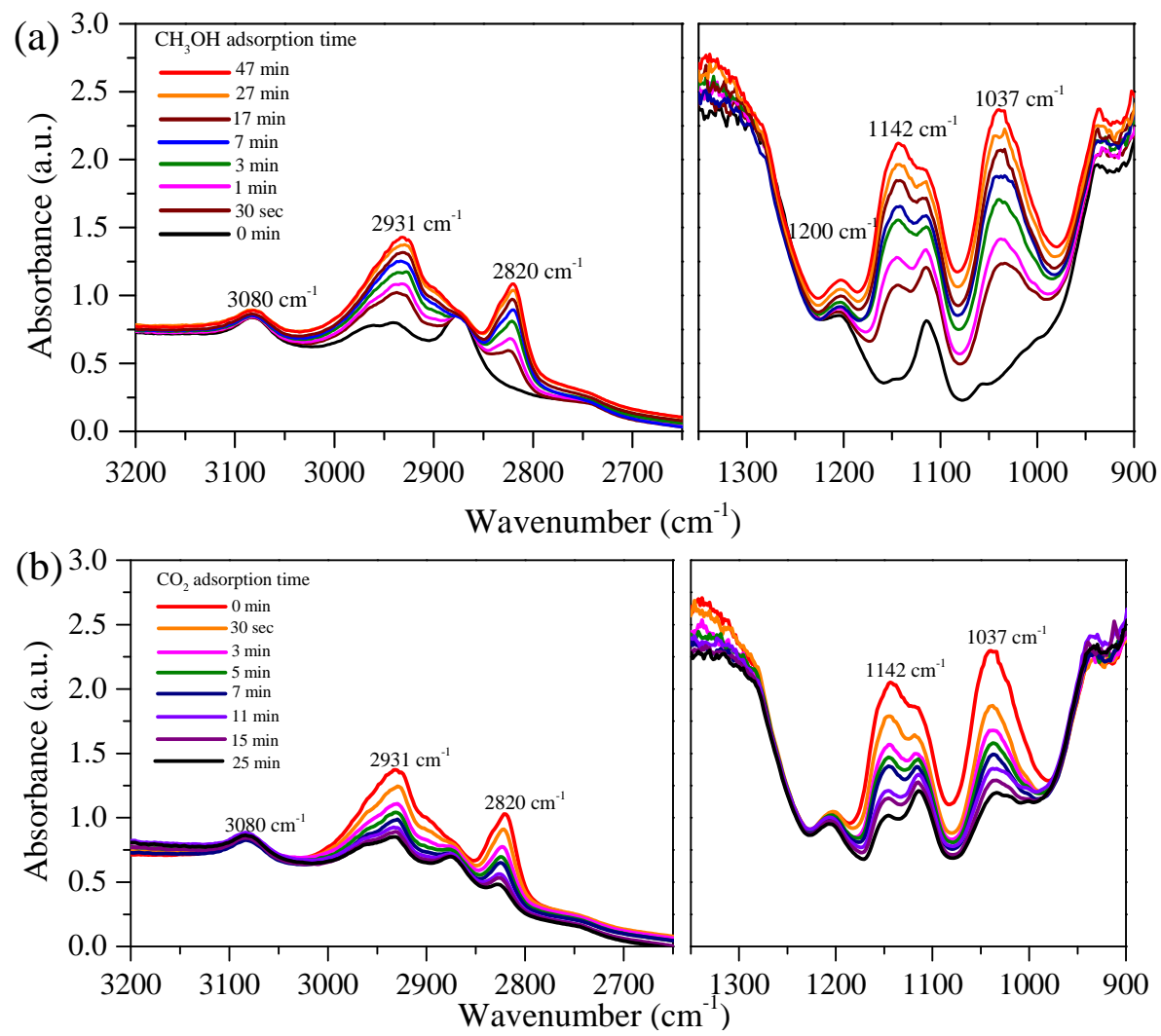

Fig. 7. In situ FT-IR spectra of (a) $\mathrm{CH}_{3} \mathrm{OH}$ adsorption on MOF-808-4, and (b) $\mathrm{CO}_{2}$ adsorption on $\mathrm{CH}_{3} \mathrm{OH}-$ pre-adsorbed MOF-808-4. 


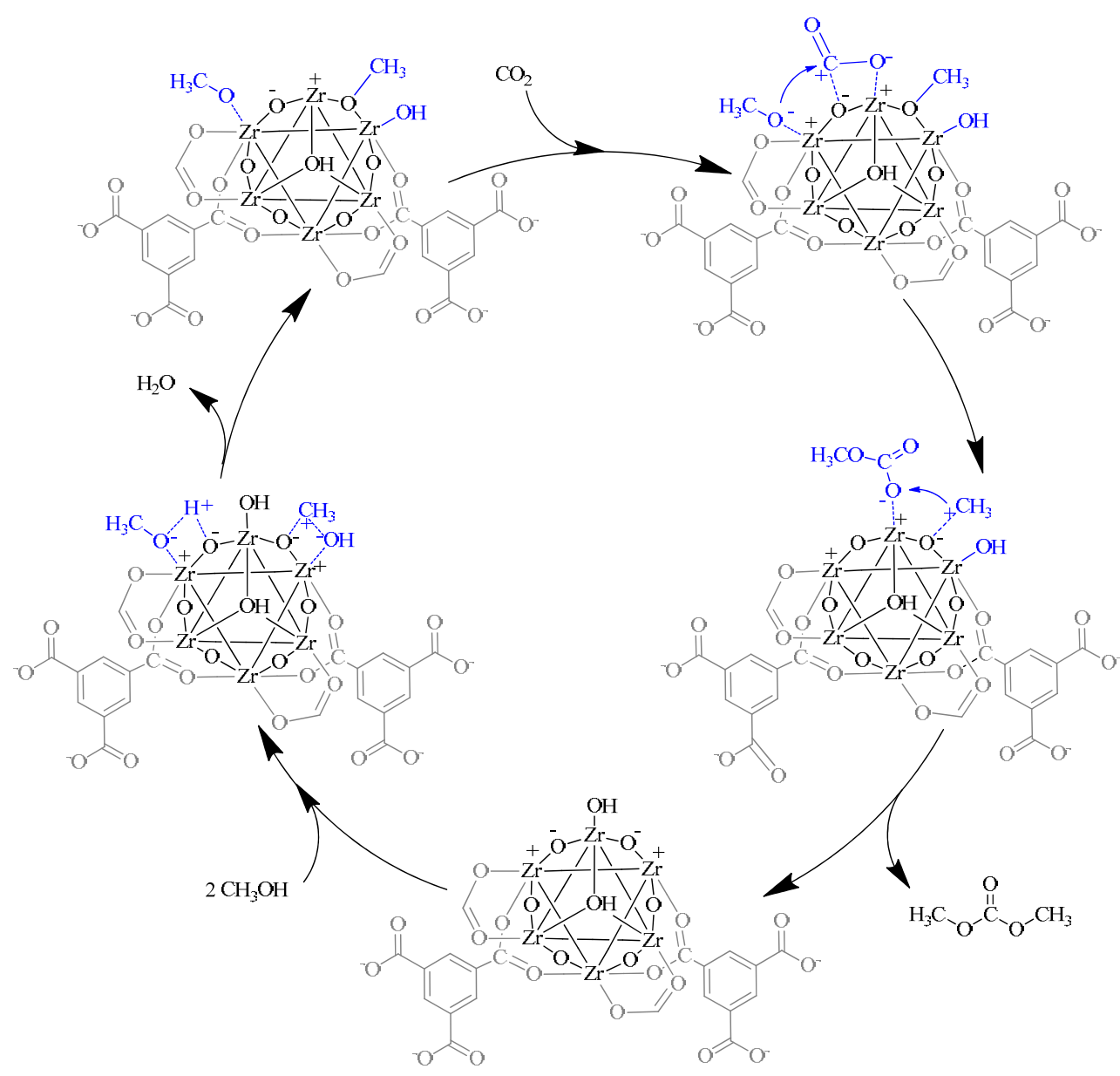

Scheme 2. Proposed reaction mechanism for the direct synthesis of $\mathrm{DMC}$ from $\mathrm{CO}_{2}$ and $\mathrm{CH}_{3} \mathrm{OH}$ over MOF-808-4.

carbonate intermediate from this pathway is much slower than that formed from the reaction of $\mathrm{t}-\mathrm{Zr}-\mathrm{OCH}_{3}$ with $\mathrm{CO}_{2}$. Therefore, it could be speculated that DMC was mainly produced by the reaction between methyl carbonate, which is formed from the reaction of $\mathrm{t}-\mathrm{Zr}-\mathrm{OCH}_{3}$ with $\mathrm{CO}_{2}$, and $\mathrm{CH}_{3}{ }^{+}$, as shown in Scheme 2.

On investigating the reaction mechanism, it is found that both the acidic sites (exposed $\mathrm{Zr}^{4+}$ and terminal hydroxyl) and the basic sites (unsaturated $\mathrm{O}^{2-}$ in $\mathrm{Zr}-\mathrm{O}-\mathrm{Zr}$ and $\mathrm{Zr}^{-} \mathrm{O}^{-}$) in $\mathrm{Zr}_{6}$ clusters of MOF-808-4 play important roles in promoting the reaction, which indicates that more number of acidic and basic sites are beneficial for enhancing the catalytic activity of MOF-808-X.

In addition, it was suggested that the formation of $\mathrm{CH}_{3}{ }^{+}$was the rate-determining step in DMC synthesis [38,48,49]. According to the mechanism of reaction over $\mathrm{ZrO}_{2}$ reported by Bell et al. [38], when $\mathrm{CO}_{2}$ is introduced to methanol-pre-adsorbed $\mathrm{ZrO}_{2}$, the decrease in intensity of the $\mathrm{C}-\mathrm{O}$ bending vibrations in the bridged methoxy $\left(\mathrm{Zr}-\left(\mathrm{OCH}_{3}\right)-\mathrm{Zr}\right)$ $\left(1032 \mathrm{~cm}^{-1}\right)$ is much slower than that in the terminal methoxy $\left(\mathrm{Zr}-\mathrm{OCH}_{3}\right)\left(1157 \mathrm{~cm}^{-1}\right)$, suggesting that the reaction between $\mathrm{Zr}-\mathrm{OCH}_{3}$ and $\mathrm{CO}_{2}$ to form $\mathrm{Zr}-\mathrm{OCOOCH}_{3}$ occurred rapidly, while the cleavage of $\mathrm{C}-\mathrm{O}$ bond in $\left.\mathrm{Zr}-\left(\mathrm{OCH}_{3}\right)-\mathrm{Zr}\right)$ to form $\mathrm{CH}_{3}{ }^{+}$was relatively slower, which limits the reaction between $\mathrm{CH}_{3}{ }^{+}$and $\mathrm{Zr}-\mathrm{OCOOCH}_{3}$ for the formation of DMC. However, in the case of
MOF-808-4, it is worth noting from Fig. 7a that the decrease in the intensity of $\mathrm{C}-\mathrm{O}$ bending vibrations in $\mathrm{Zr}-\left(\mathrm{OCH}_{3}\right)-\mathrm{Zr}(1037$ $\mathrm{cm}^{-1}$ ) was more pronounced than that in $\mathrm{ZrO}_{2}$ reported by Bell et al. [38], indicating that the $\mathrm{C}-\mathrm{O}$ bond of $\mathrm{Zr}-\left(\mathrm{OCH}_{3}\right)-\mathrm{Zr}$ over MOF-808-4 could be rapidly cleaved to form $\mathrm{CH}_{3}{ }^{+}$, which could then react with the generated intermediate $\mathrm{Zr}-\mathrm{OCOOCH}_{3}$ to form DMC $[11,38,48]$. The rapid cleavage of $\mathrm{C}-\mathrm{O}$ bond in the bridged methoxy $\left(\mathrm{Zr}-\left(\mathrm{OCH}_{3}\right)-\mathrm{Zr}\right)$ over MOF-808-4 compared to that over $\mathrm{ZrO}_{2}$ is probably attributed to the neighboring acidic-basic sites in $\mathrm{Zr}_{6}$ nodes of MOF-808-4 [9,38] (six $\mathrm{Zr}$ atoms of $\mathrm{Zr}_{6}$ node are arrayed as an octahedron in which the acidic-basic sites, including the Lewis acidic sites (exposed $\mathrm{Zr}^{4+}$ ), basic sites (unsaturated $\mathrm{O}^{2-}$ in $\mathrm{Zr}-\mathrm{O}-\mathrm{Zr}$ or $\mathrm{Zr}-\mathrm{O}^{-}$), and terminal hydroxyl are adjacent to each other $[55,56]$, see Scheme 2). Tomishige et al. [9] and Bell et al. [38] revealed that the neighboring acidic sites (exposed $\mathrm{Zr}^{4+}$ and hydroxyl) and basic sites (unsaturated $\mathrm{O}^{2-}$ in $\mathrm{Zr}-\mathrm{O}-\mathrm{Zr}$ or $\mathrm{Zr}-\mathrm{O}^{-}$) in $\mathrm{ZrO}_{2}$ are favorable for the cleavage of $\mathrm{C}-\mathrm{O}$ bond in $\mathrm{Zr}-\left(\mathrm{OCH}_{3}\right)-\mathrm{Zr}$ to form $\mathrm{CH}_{3}{ }^{+}$and the bonding of $\mathrm{CH}_{3}{ }^{+}$with the methyl carbonate species to form DMC. Gates et al. [55] also found that the Zr-based MOF catalyst UiO-66 shows much higher activity than $\mathrm{ZrO}_{2}$ in the reaction of ethanol dehydration to ether, since the larger number of the neighboring acidic-basic sites in the highly dispersed $\mathrm{Zr}_{6}$ nodes of UiO-66 allows a rapid bonding of ethanol with ethoxy adsorbed on the neighboring sites of $\mathrm{Zr}_{6}$ nodes, facilitating the bimolecular ether 
formation. Therefore, it is reasonable to infer that the neighboring acidic-basic sites in $\mathrm{Zr}_{6}$ nodes of MOF-808-4 may also allow catalytic bonding of $\mathrm{CH}_{3}{ }^{+}$(arising from $\mathrm{C}-\mathrm{O}$ bond cleavage of $\left.\mathrm{Zr}-\left(\mathrm{OCH}_{3}\right)-\mathrm{Zr}\right)$ with the neighboring $\mathrm{Zr}-\mathrm{OCOOCH}_{3}$ on $\mathrm{Zr}_{6}$ nodes, thereby leading to the rapid formation of DMC $[9,55]$. Based on the results discussed above, we suppose that the rapid cleavage of $\mathrm{C}-\mathrm{O}$ bond in the bridged methoxy $\left(\mathrm{Zr}-\left(\mathrm{OCH}_{3}\right)-\mathrm{Zr}\right)$ to form $\mathrm{CH}_{3}{ }^{+}$(the rate-determining step in DMC synthesis) may be another important factor contributing to the high activity of MOF-808-4.

\subsubsection{Effects of reaction parameters on DMC yield}

MOF-808-4 was used to gain further insights into the effects of reaction parameters, including the reaction temperature, reaction pressure, amount of TMM, and reaction time on the DMC yield (Fig. 8). Experimental results show that the optimal reaction conditions for DMC synthesis from $\mathrm{CO}_{2}$ and $\mathrm{CH}_{3} \mathrm{OH}$ were: reaction temperature of $140{ }^{\circ} \mathrm{C}, \mathrm{CO}_{2}$ pressure of $12 \mathrm{MPa}$, TMM amount of $100 \mathrm{mmol}$, and reaction time of $48 \mathrm{~h}$, under which, the highest DMC yield of $21.5 \%$ was obtained (Fig. $8 d$ ). DMC yield obtained under the optimal reaction conditions over MOF-808-4 was compared with that over several other catalysts developed in recent years (Table 4). It was found that the optimal DMC yield over MOF-808-4 was higher or comparable to that obtained using the same/similar dehydrating agent such as DMP, TMM, and butylene oxide (Entries 1 to 6), indicating that MOF-808-4 could be an efficient catalyst for the direct synthesis of $\mathrm{DMC}$ from $\mathrm{CO}_{2}$ and $\mathrm{CH}_{3} \mathrm{OH}$. However, it should be noted that the optimal DMC yield over MOF-808-4 was lower than that over $\mathrm{CeO}_{2}$, with 2-cyanopyridine as the dehydrating agent (Entry 7), reported by Tomishige et al. [11]. Thus, we suppose that 2-cyanopyridine might be a better dehydrating agent in the reaction. Hence, the formation of DMC over MOF-808-4 by using 2-cyanopyridine as the dehydrating agent was also carried out, but the DMC yield achieved over MOF-808-4 (34.3\%, Entry 9) was still lower than that over $\mathrm{CeO}_{2}$ (97\%, Entry 7) [11]. This is probably because MOF-808-4 showed no catalytic activity in the reaction between $\mathrm{H}_{2} \mathrm{O}$ and TMM or 2-cyanopyridine, while $\mathrm{CeO}_{2}$ can not only catalyze the reaction between $\mathrm{CO}_{2}$ and methanol, but also can show high catalytic activity in the hydration of 2-cyanopyridine, which could further accelerate the formation of DMC $[11,57]$.

In order to study the possible contribution of homogeneous catalytic reaction due to active species leaching, MOF-808-4 was removed from the reaction medium by filtration after reacting for $4 \mathrm{~h}$. It was found that only $1.3 \%$ of $\mathrm{Zr}^{4+}$ was leached from MOF-808-4 in the filtrate, as confirmed by ICP-OES. In addition, no further increase in the DMC yield in the filtrate was observed after the catalyst removal (Fig. 8d), indicating that the reaction was catalyzed heterogeneously.

\subsubsection{Reusability}

The reusability of MOF-808-X was tested under the optimum reaction conditions. After each reaction, the catalyst was collected by centrifugation and washed with $\mathrm{CH}_{3} \mathrm{OH}$, followed by drying at $150{ }^{\circ} \mathrm{C}$ for $12 \mathrm{~h}$. As illustrated in Fig. S6A, although the reusability of all the MOF-808-X was not good, MOF-808-3 and -4 exhibited a relatively better reusability. To understand
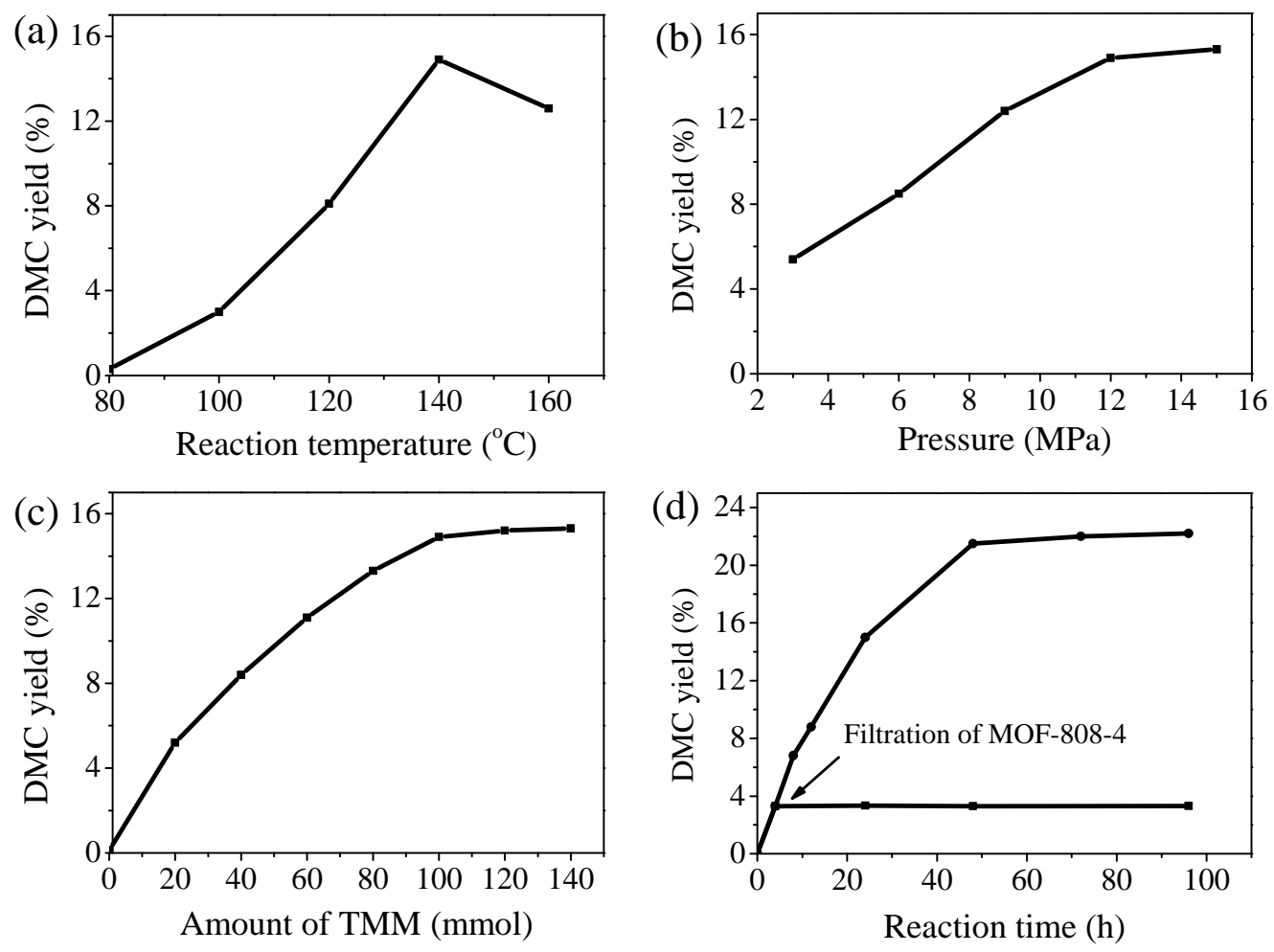

Fig. 8. Dependence of DMC yield on (a) the reaction temperature at $12 \mathrm{MPa}, 100 \mathrm{mmol} \mathrm{TMM}$, and $24 \mathrm{~h}$, (b) the reaction pressure at $140{ }^{\circ} \mathrm{C}, 100 \mathrm{mmol}$ $\mathrm{TMM}$, and $24 \mathrm{~h},(\mathrm{c})$ the amount of TMM at $140{ }^{\circ} \mathrm{C}, 12 \mathrm{MPa}$, and $24 \mathrm{~h}$, and (d) the reaction time at $140{ }^{\circ} \mathrm{C}, 12 \mathrm{MPa}$, and $100 \mathrm{mmol} \mathrm{TMM}$. 
Table 4

Comparison of the DMC yield over MOF-808-4 with that reported in the literature.

\begin{tabular}{|c|c|c|c|c|c|c|c|}
\hline Entry & Catalyst & Dehydrating agent & $P_{\mathrm{CO} 2}(\mathrm{MPa})$ & $T\left({ }^{\circ} \mathrm{C}\right)$ & $T(\mathrm{~h})$ & DMC yield (\%) & Ref. \\
\hline 1 & $\mathrm{Ce}_{0.2} \mathrm{Zr}_{0.8} \mathrm{O}_{2}$ & $\mathrm{DMP}^{\mathrm{a}}$ & $200 \mathrm{mmol}$ & 120 & 140 & 7.2 & [13] \\
\hline 2 & $\mathrm{Bu}_{2} \mathrm{Sn}(\mathrm{OMe})$ & $\mathrm{DMP}^{\mathrm{a}}$ & $200 \mathrm{mmol}$ & 180 & 24 & 9.4 & {$[51]$} \\
\hline 3 & $\mathrm{ZrO}_{2}-\mathrm{MgO}$ & Butylene oxide & 9 & 150 & 8 & 6.2 & [58] \\
\hline 4 & $\mathrm{ZrO}_{2}-\mathrm{KCl}-\mathrm{MgO}$ & Butylene oxide & 4 & 150 & 8 & 7.2 & [47] \\
\hline 5 & $\mathrm{Ce}_{0.5} \mathrm{Zr}_{0.5} \mathrm{O}_{2} /$ Graphene & TMM & 12 & 110 & 16 & 23.2 & {$[17]$} \\
\hline 6 & $\mathrm{Ce}_{0.5} \mathrm{Zr}_{0.5} \mathrm{O}_{2}$ & TMM & 12 & 140 & 34 & 10.4 & [18] \\
\hline 7 & $\mathrm{CeO}_{2}$ & 2-cyanopyridine & 16 & 120 & 16 & 97.0 & [11] \\
\hline 8 & MOF-808-4 & TMM & 12 & 140 & 48 & 21.5 & This work \\
\hline 9 & MOF-808-4 & 2-cyanopyridine & 12 & 140 & 48 & 34.3 & This work \\
\hline
\end{tabular}

a DMP: Dimethoxymethane.

the reason, all the recycled MOF-808-X catalysts were characterized by XRD. As can be seen in Fig. S6B, after cycle 1, the structures of MOF-808-3 and -4 were retained, but the intensity of the characteristic peaks slightly decreased, which might account for the slight decrease in the DMC yield over MOF-808-3 and -4 in cycle 2 . However, for MOF-808-0.5, $-1,-2$, and 5 , the DMC yield over these catalysts dramatically decreased after cycle 1 , which was probably due to a severe collapse of the frame structure as indicated by the XRD patterns that show a dramatic decrease in the intensity of the characteristic peaks of these samples. The relatively better reusability of MOF-808-3 and -4 could be attributed to their good crystallinity, since the frame structure of MOF catalyst with better crystallinity could be retained better during the reaction $[59,60]$. Although the reusability of MOF-808-X was far from that required for practical applications, the high activity of MOF-808-4 in cycle 1 and the relationship between the stability and crystallinity of MOF-808-X provide us a direction for the future development of more efficient and stable MOF-based catalysts for DMC synthesis from $\mathrm{CO}_{2}$ and methanol.

\section{Conclusions}

In summary, MOF-808-X (6-connected) have been proven to be effective for the direct synthesis of DMC from $\mathrm{CO}_{2}$ and $\mathrm{CH}_{3} \mathrm{OH}$, with TMM as the dehydrating agent. The $\mathrm{ZrOCl}_{2} \cdot 8 \mathrm{H}_{2} \mathrm{O} / \mathrm{BTC}$ molar ratio has significant effect on the physicochemical properties and catalytic performances of MOF-808-X. By regulating the molar ratio of $\mathrm{ZrOCl}_{2} \cdot 8 \mathrm{H}_{2} \mathrm{O} / \mathrm{BTC}$ for MOF-808-X synthesis, the amount of the redundant BTC or zirconium clusters trapped in the micropores can be reduced. As a result, MOF-808-4, with almost no redundant BTC or zirconium clusters trapped in the micropores, exhibited the largest micropore size, surface area, and the number of acidic-basic sites. Consequently, MOF-808-4 showed the best activity among MOF-808-X, with the highest DMC yield of $21.5 \%$ under the optimum reaction conditions. However, its comparison with UiO-66-24 (12-connected) indicated that despite MOF-808-4 had lower surface area and fewer acidic-basic sites than UiO-66-24, it had lower connectivity that provided larger micropore size for the higher accessibility of the active sites located in the micropores to the reactants, leading to the higher activity of MOF-808-4 over Ui0-66-24. This indicates that in addition to surface area and the number of active sites, the mi- cropore size also has a significant effect on the improvement of the catalytic activity. Furthermore, mechanistic studies suggested that the rapid formation of $\mathrm{CH}_{3}{ }^{+}$(rate-determining step in DMC synthesis) over MOF-808-4 also contributes to its high activity. Reusability tests showed that although all the MOF-808-X catalysts were not satisfactory, those with good crystallinity were relative more stable. Hence, more efforts are required to explore other efficient and stable MOF catalysts for DMC synthesis from $\mathrm{CO}_{2}$ and $\mathrm{CH}_{3} \mathrm{OH}$ in the future studies.

\section{References}

[1] G. Fiorani, A. Perosa, M. Selva, Green Chem., 2018, 20, 288-322.

[2] S. Huang, B. Yan, S. Wang, X. Ma, Chem. Soc. Rev., 2015, 44, 3079-3116.

[3] S. Pan, L. Zheng, R. Nie, S. Xia, P. Chen, Z. Hou, Chin. J. Catal., 2012, $33,1772-1777$.

[4] D. Delledonne, F. Rivetti, U. Romano, Appl. Catal. A, 2001, 221, 241-251.

[5] Y. Cao, H. Cheng, L. Ma, F. Liu, Z. Liu, Catal. Surv. Asia, 2012, 16, 138-147.

[6] M. Honda, M. Tamura, Y. Nakagawa, K. Tomishige, Catal. Sci. Technol., 2014, 4, 2830.

[7] Y. Liao, F. Li, X. Dai, N. Zhao, F. Xiao, Chin. J. Catal., 2017, 38, 1860-1869.

[8] K. Tomishige, T. Sakaihori, Y. Ikeda, K. Fujimoto, Catal. Lett. 1999, $58,225-229$.

[9] K. Tomishige, Y. Ikeda, T. Sakaihori, K. Fujimoto, J. Catal., 2000, 192, 355-362.

[10] T. Akune, Y. Morita, S. Shirakawa, K. Katagiri, K. Inumaru, Langmuir, 2018, 34, 23-29.

[11] M. Honda, M. Tamura, Y. Nakagawa, K. Nakao, K. Suzuki, K. Tomishige, J. Catal., 2014, 318, 95-107.

[12] S. Wang, L. Zhao, W. Wang, Y. Zhao, G. Zhang, X. Ma, J. Gong, Nanoscale, 2013, 5, 5582-5588.

[13] K. Tomishige, K. Kunimori, Appl. Catal. A, 2002, 237, 103-109.

[14] A. Li, Y. Pu, F. Li, J. Luo, N. Zhao, F. Xiao, J. $\mathrm{CO}_{2}$ Utiliz., 2017, 19, 33-39.

[15] Y. Pu, K. Xuan, F. Wang, A. Li, N. Zhao, F. Xiao, RSC Adv., 2018, 8, 27216-27226.

[16] M. Aresta, A. Dibenedetto, C. Pastore, A. Angelini, B. Aresta, I. Pápai, J. Catal., 2010, 269, 44-52.

[17] R. Saada, S. Kellici, T. Heil, D. Morgan, B. Saha, Appl. Catal. B, 2015, 168-169, 353-362.

[18] Z. Zhang, Z. Liu, J. Lu, Z.-T. Liu, Ind. Eng. Chem. Res., 2011, 50, 1981-1988.

[19] O. Arbeláez, A. Orrego, F. Bustamante, A. L. Villa, Catal. Lett., 2016, 


\section{Graphical Abstract}

Chin. J. Catal., 2019, 40: 553-566 doi: S1872-2067(19)63291-2

Metal-organic frameworks MOF-808-X as highly efficient catalysts for direct synthesis of dimethyl carbonate from $\mathrm{CO}_{2}$ and methanol

Keng Xuan, Yanfeng Pu, Feng Li, Jing Luo, Ning Zhao *, Fukui Xiao*

Institute of Coal Chemistry, Chinese Academy of Sciences; University of Chinese Academy of Sciences

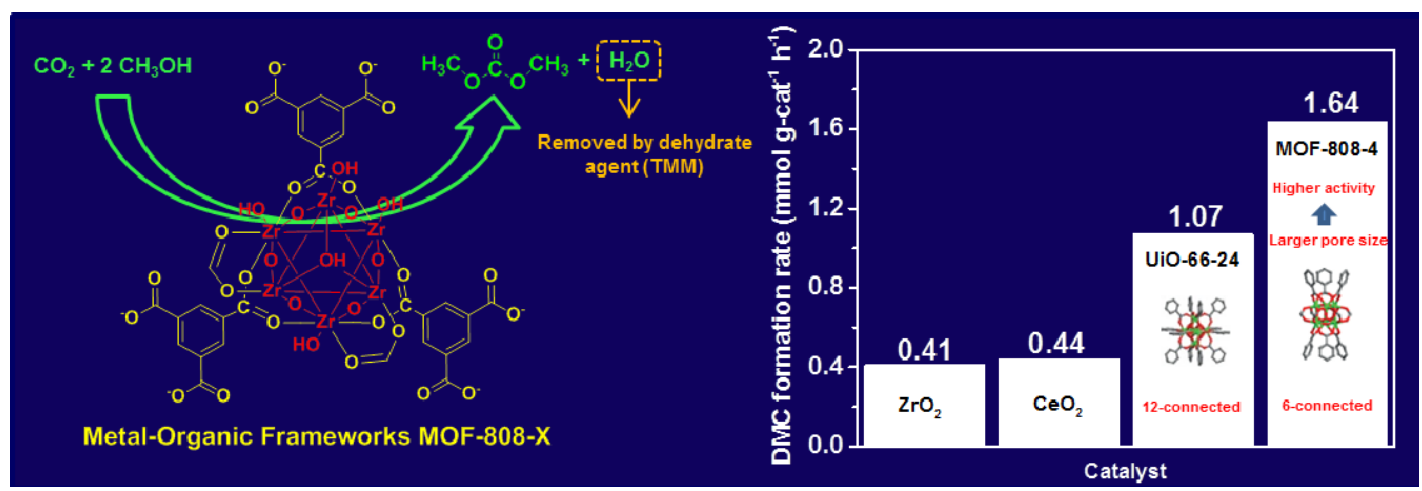

Metal-organic framework catalysts MOF-808-X were highly active for the direct synthesis of dimethyl carbonat (DMC) from $\mathrm{CO}_{2}$ and $\mathrm{CH}_{3} \mathrm{OH}$. The effects of the $\mathrm{ZrOCl}_{2} \cdot 8 \mathrm{H}_{2} \mathrm{O} / 1,3,5$-benzenetricarboxylic acid (BTC) molar ratio on the physicochemical properties and catalytic activities of MOF-808-X were clarified.

$146,725-733$.

[20] A. H. Tamboli, A. A. Chaugule, H. Kim, Chem. Eng. J., 2017, 323, 530-544.

[21] G. C. Shearer, S. Chavan, S. Bordiga, S. Svelle, U. Olsbye, K. P. Lillerud, Chem. Mater., 2016, 28, 3749-3761.

[22] S. Y. Moon, Y. Liu, J. T. Hupp, O. K. Farha, Angew. Chem. Int. Ed., 2015, 54, 6795-6799.

[23] Y. Liu, R. C. Klet, J. T. Hupp, O. Farha, Chem. Commun., 2016, 52, 7806-7809.

[24] K. Xuan, Y. Pu, F. Li, A. Li, J. Luo, L. Li, F. Wang, N. Zhao, F. Xiao, J. $\mathrm{CO}_{2}$ Utiliz., 2018, 27, 272-282.

[25] M. Saito, T. Toyao, K. Ueda, T. Kamegawa, Y. Horiuchi, M. Matsuoka, Dalton Trans., 2013, 42, 9444-9447.

[26] R. S. Mehare, S. P. Ranganath, V. Chaturvedi, M. V. Badiger, M. V. Shelke, Energy Fuels, 2018, 32, 908-915.

[27] C. Ardila-Suárez, S. Perez-Beltran, G. Ramírez-Caballero, P. B. Balbuena, Catal. Sci. Technol., 2018, 8, 847-857.

[28] Z. Q. Li, J. C. Yang, K. W. Sui, N. Yin, Mater. Lett., 2015, 160, 412-414.

[29] Y. Peng, H. Huang, Y. Zhang, C. Kang, S. Chen, L. Song, D. Liu, C. Zhong, Nat. Commun., 2018, 9, 187.

[30] G. Cai, H. Jiang, Angew. Chem. Int. Ed., 2017, 56, 563-567.

[31] L. H. Wee, F. Bonino, C. Lamberti, S. Bordiga, J. A. Martens, Green Chem., 2014, 16, 1351-1357.

[32] H. Furukawa, F. Gandara, Y. B. Zhang, J. Jiang, W. L. Queen, M. R. Hudson, O. M. Yaghi, J. Am. Chem. Soc., 2014, 136, 4369-4381.

[33] G. C. Shearer, S. Chavan, J. Ethiraj, J. G. Vitillo, S. Svelle, U. Olsbye, C. Lamberti, S. Bordiga, K. P. Lillerud, Chem. Mater., 2014, 26, 4068-4071.

[34] S. Hinokuma, G. Wiker, T. Suganuma, A. Bansode, D. Stoian, S. Caminero Huertas, S. Molina, A. Shafir, M. Rønning, W. van Beek, A. Urakawa, Eur. J. Inorg. Chem., 2018, 2018, 1847-1853.

[35] H. Ranjan Sahu, G. Ranga Rao, Bull. Mater. Sci., 2000, 23, 349-354.

[36] Y. Wang, L. Li, P. Dai, L. Yan, L. Cao, X. Gu, X. Zhao, J. Mater. Chem. A,
2017, 5, 22372-22379.

[37] D.Y. Hong, Y. K. Hwang, C. Serre, G. Férey, J. S. Chang, Adv. Funct. Mater., 2009, 19, 1537-1552.

[38] K. T. Jung, A. T. Bell, J. Catal., 2001, 204, 339-347.

[39] F. Vermoortele, B. Bueken, G. Le Bars, B. Van de Voorde, M. Vandichel, K. Houthoofd, A. Vimont, M. Daturi, M. Waroquier, V. Van Speybroeck, C. Kirschhock, D. E. De Vos, J. Am. Chem. Soc., 2013, 135, 11465-11468.

[40] R. C. Klet, Y. Liu, T. C. Wang, J. T. Hupp, O. K. Farha, J. Mater. Chem. A, 2016, 4, 1479-1485.

[41] S. Øien, D. Wragg, H. Reinsch, S. Svelle, S. Bordiga, C. Lamberti, K. P. Lillerud, Cryst. Growth Des., 2014, 14, 5370-5372.

[42] P. He, J. Xu, V. V. Terskikh, A. Sutrisno, H. Y. Nie, Y. Huang, J. Phy. Chem. C, 2013, 117, 16953-16960.

[43] P. Gao, F. Li, H. Zhan, N. Zhao, F. Xiao, W. Wei, L. Zhong, H. Wang, Y. Sun, J. Catal., 2013, 298, 51-60.

[44] N. D. Didier Tichit, Bernard Coq, Robert Durand, Chem. Mater., 2002, 14, 1530-1538.

[45] F. Bustamante, A. F. Orrego, S. Villegas, A. L. Villa, Ind. Eng. Chem. Res., 2012, 51, 8945-8956.

[46] B. Y. Yu, M. K. Chen, I. L. Chien, Ind. Eng. Chem. Res., 2018, 57, 639-652.

[47] V. Eta, P. Mäki-Arvela, A. R. Leino, K. Kordas, T. Salmi, D. Yu. Murzin, J. P. Mikkola, Ind. Eng. Chem. Res., 2010, 49, 9609-9617.

[48] Y. Ikeda, M. Asadullah, K. Fujimoto, K. Tomishige, J. Phys. Chem. B, 2001, 105, 10653-10658.

[49] H. J. Lee, S. Park, J. C. Jung, I. K. Song, Korean J. Chem. Eng., 2011, 28, 1518-1522.

[50] H. J. Lee, W. Joe, I. K. Song, Korean J. Chem. Eng., 2011, 29, 317-322.

[51] H. J. Lee, W. Joe, J. C. Jung, I. K. Song, Korean J. Chem. Eng., 2012, 29, 1019-1024.

[52] H. Li, X. Jiao, L. Li, N. Zhao, F. Xiao, W. Wei, Y. Sun, B. Zhang, Catal. Sci. Technol., 2015, 5, 989-1005. 
[53] L. Chen, S. Wang, J. Zhou, Y. Shen, Y. Zhao, X. Ma, RSC Adv., 2014, 4, 30968-30975.

[54] D. Yang, V. Bernales, T. Islamoglu, O. K. Farha, J. T. Hupp, C. J. Cramer, L. Gagliardi, B. C. Gates, J. Am. Chem. Soc., 2016, 138, 15189-15196.

[55] D. Yang, M. A. Ortuno, V. Bernales, C. J. Cramer, L. Gagliardi, B. C. Gates, J. Am. Chem. Soc., 2018, 140, 3751-3759.

[56] Y. Bai, Y. Dou, L. H. Xie, W. Rutledge, J. R. Li, H. C. Zhou, Chem. Soc. Rev., 2016, 45, 2327-2367.
[57] M. Honda, M. Tamura, Y. Nakagawa, S. Sonehara, K. Suzuki, K. Fujimoto, K. Tomishige, ChemSusChem, 2013, 6, 1341-1344.

[58] V. Eta, P. Mäki-Arvela, J. Wärnå, T. Salmi, J.P. Mikkola, D. Y. Murzin, Appl. Catal. A, 2011, 404, 39-46.

[59] A. J. Howarth, Y. Liu, P. Li, Z. Li, T. C. Wang, J. T. Hupp, O. K. Farha, Nat. Rev. Mater., 2016, 1, 15018.

[60] M. Lin Foo, S. Horike, T. Fukushima, Y. Hijikata, Y. Kubota, M. Takata, S. Kitagawa, Dalton Trans., 2012, 41, 13791-13794.

\title{
金属有机框架MOF-808-X高效催化 $\mathrm{CO}_{2}$ 和甲醇直接合成碳酸二甲酯
}

\author{
宣 锃 ${ }^{\mathrm{a}, \mathrm{b}}$, 蒲彦锋 ${ }^{\mathrm{a}}$, 李 枫 ${ }^{\mathrm{a}}$, 倠 京 ${ }^{\mathrm{a}, \mathrm{b}}$, 赵 宁 ${ }^{\mathrm{a},{ }^{*}}$, 肖福魁 ${ }^{\mathrm{a}, \text {, }}$ \\ a中国科学院山西煤炭化学研究所煤转化国家重点实验室, 山西太原030001 \\ b 中国科学院大学, 北京100049
}

\begin{abstract}
摘要: 碳酸二甲酯(DMC)是一种重要的绿色无毒化工原料, 其分子结构中含有甲基、甲氧基和羰基等官能团. DMC既可以 替代卤代甲烷和硫酸二甲酯用作甲基化试剂, 替代剧毒的光气用作羰基化试剂, 也可以与醇类、酯类及氨基醇类进行酯交 换反应用于合成树脂和精细化学品. 此外, DMC因具有相容性好、含氧量高和饱和蒸气压低等特点, 还可用作低毒溶剂和 燃油添加剂. 目前, 已报道的DMC合成方法主要包括光气法、甲醇氧化羰基化法、酯交换法、尿素醇解法和直接合成法. 其 中, 以 $\mathrm{CO}_{2}$ 和甲醇为原料直接合成DMC的方法受到广泛关注. 该方法不仅具有原料价格低廉、工艺简单、原子经济性高的 优点, 还可以将温室气体 $\mathrm{CO}_{2}$ 资源化利用, 有望成为未来生产 $\mathrm{DMC}$ 的一条全新的高效途径. 目前, 用于该反应的催化剂研 究主要集中在金属氧化物和改性金属氧化物上, 这些催化剂存在比表面积较小、活性位点数量不足以及活性不高的缺点.

本文针对传统金属氧化物的缺点, 合成了一系列锆基金属有机框架催化剂MOF-808-X $\left(\mathrm{X}\right.$ 为 $\mathrm{ZrOCl}_{2} \cdot 8 \mathrm{H}_{2} \mathrm{O} /$ 均苯三甲酸 (BTC)的摩尔比), 并将其用于催化 $\mathrm{CO}_{2}$ 和甲醇合成DMC, 系统考察了 MOF-808-X合成过程中 $\mathrm{ZrOCl}_{2} \cdot 8 \mathrm{H}_{2} \mathrm{O} / \mathrm{BTC}$ 摩尔比对 MOF-808-X催化剂组成、比表面积、孔道结构以及酸碱位点数量的影响, 探讨了MOF-808-X催化剂物化性质与其催化性能 之间的关系. 结果表明, 通过调控 $\mathrm{ZrOCl}_{2} \cdot 8 \mathrm{H}_{2} \mathrm{O} / \mathrm{BTC}$ 摩尔比, 可以减少堵塞在MOF-808-X微孔中未反应的配体BTC或氧化 锆原子簇的量, 提高MOF-808-X的比表面积、微孔孔径以及酸碱位点数量, 从而显著提升MOF-808-X催化剂的催化活性. 当 $\mathrm{ZrOCl}_{2} \cdot 8 \mathrm{H}_{2} \mathrm{O} / \mathrm{BTC}$ 摩尔比=4时, MOF-808-4催化剂具有最大的比表面积、最大的微孔孔径和最多的酸碱性位点, 因而表现 出最高的催化活性. 与我们之前报道的UiO-6-24相比, 虽然MOF-808-4的比表面积和酸碱位点数更小, 但由于MOF-808-4 具有更大的微孔孔径 $(1.8 \mathrm{~nm})$, 其微孔内的活性位点具有更高的催化效率, MOF-808-4表现出了更高的催化活性. 原位红外 光谱结果表明, 酸性位点活化甲醇生成甲基阳离子的过程是该反应的速率控制步骤, 由于MOF-808-4中 $\mathrm{Zr}_{6}$ 原子簇上酸碱位 点相互邻近, 吸附在相邻碱性位点上的中间产物羰基甲氧基可以与酸性位点上的甲基阳离子迅速反应, 促进甲基阳离子和 DMC的生成, 从而进一步提高MOF-808-4的催化活性. 此外, 催化剂重复利用实验结果表明, MOF-808-X催化剂结晶度越 好, 催化剂重复利用性能越好. MOF-808-X催化剂在 $\mathrm{CO}_{2}$ 和甲醇直接合成DMC反应中的成功应用可为开发用于该反应的 高效非均相催化剂提供新的思路.
\end{abstract}

关键词: 金属有机框架; MOF-808; 微孔孔径; 二氧化碳; 甲醇; 碳酸二甲酯

收稿日期: 2018-11-08. 接受日期: 2018-12-26. 出版日期: 2019-04-05.

*通讯联系人.电话: (0351)4041153; 传真: (0351)4046129; 电子信箱: zhaoning@sxicc.ac.cn

\#通讯联系人. 电话: (0351)4041153; 传真: (0351)4046129; 电子信箱: xiaofk@sxicc.ac.cn

基金来源：山西省自然科学基金(201601D102006); 山西省青年科学基金(201701D221052); 国家自然科学基金(21776294); 山西 省重点科技攻关项目(MD2014-09, MD2014-10); 煤转化国家重点实验室自主研究课题(2018BWZ002).

本文的电子版全文由Elsevier出版社在ScienceDirect上出版(http://www.sciencedirect.com/science/journal/18722067). 